\title{
Glutamate Transporter Coupling to Na,K-ATPase
}

\author{
Erin M. Rose, ${ }^{1,2}$ Joseph C. P. Koo, ${ }^{1}$ Jordan E. Antflick, ${ }^{1}$ Syed M. Ahmed, ${ }^{1}$ Stephane Angers, ${ }^{1,3}$ and David R. Hampson ${ }^{1,2}$ \\ ${ }^{1}$ Department of Pharmaceutical Sciences, Leslie Dan Faculty of Pharmacy and Departments of ${ }^{2}$ Pharmacology and ${ }^{3}$ Biochemistry, Faculty of Medicine, \\ University of Toronto, Toronto, Ontario M5S 3M2, Canada
}

Deactivation of glutamatergic signaling in the brain is mediated by glutamate uptake into glia and neurons by glutamate transporters. Glutamate transporters are sodium-dependent proteins that putatively rely indirectly on Na,K-ATPases to generate ion gradients that drive transmitter uptake. Based on anatomical colocalization, mutual sodium dependency, and the inhibitory effects of the Na,K-ATPase inhibitor ouabain on glutamate transporter activity, we postulated that glutamate transporters are directly coupled to Na,K-ATPase and that $\mathrm{Na}, \mathrm{K}-\mathrm{ATPa} e$ is an essential modulator of glutamate uptake.

$\mathrm{Na}, \mathrm{K}-\mathrm{ATPa} e$ was purified from rat cerebellum by tandem anion exchange and ouabain affinity chromatography, and the cohort of associated proteins was characterized by mass spectrometry. The $\alpha 1-\alpha 3$ subunits of Na,K-ATPase were detected, as were the glutamate transporters GLAST and GLT-1, demonstrating that glutamate transporters copurify with Na,K-ATPases. The link between glutamate transporters and Na,K-ATPase was further established by coimmunoprecipitation and colocalization. Analysis of the regulation of

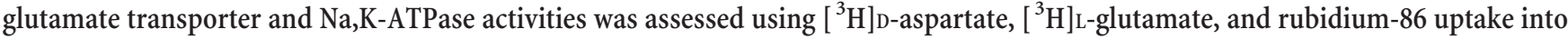
synaptosomes and cultured astrocytes. In synaptosomes, ouabain produced a dose-dependent inhibition of glutamate transporter and $\mathrm{Na}, \mathrm{K}$-ATPase activities, whereas in astrocytes, ouabain showed a bimodal effect whereby glutamate transporter activity was stimulated at $1 \mu \mathrm{M}$ ouabain and inhibited at higher concentrations. The effects of protein kinase inhibitors on $\left[{ }^{3} \mathrm{H}\right] \mathrm{D}$-aspartate uptake indicated the selective involvement of Src kinases, which are probably a component of the Na,K-ATPase/glutamate transporter complex. These findings demonstrate that glutamate transporters and $\mathrm{Na}, \mathrm{K}-\mathrm{ATPases}$ are part of the same macromolecular complexes and operate as a functional unit to regulate glutamatergic neurotransmission.

\section{Introduction}

Within the family of excitatory amino acid transporters (EAATs), the glutamate transporters GLAST (also known as EAAT1) and particularly GLT-1 (also known as EAAT2) are quantitatively the primary players in mediating glutamate uptake in the mammalian CNS (Amara and Fontana, 2002; Shigeri et al., 2004; Kanner, 2006). Glutamate transporters are sodium-dependent proteins that rely on sodium and potassium gradients generated principally by Na,K-ATPase. Na,K-ATPase, also known as the sodium/ potassium pump, is a ubiquitously expressed membrane-bound enzyme consisting of an $\alpha$ subunit, which contains the binding sites for ATP and the highly potent and selective inhibitor ouabain, and a heavily glycosylated $\beta$ subunit that is required for full enzymatic activity; the $\beta$ subunit also functions as an intercellular adhesion protein (Larre et al., 2006; Vagin et al., 2006).

In addition to the putative indirect reliance on $\mathrm{Na}, \mathrm{K}-\mathrm{ATP}$ ase through ion gradients, previous work has hinted at the possibility of a more extensive link between glutamate transporters and $\mathrm{Na}, \mathrm{K}-\mathrm{ATPa} e$. Ouabain has been shown to impair glutamate transporter activity, and injection of ouabain into neonatal rat

Received March 5, 2009; revised May 15, 2009; accepted May 27, 2009.

This work was funded by the Canadian Institutes for Health Research and by a graduate scholarship (E.M.R.) from the Natural Sciences and Engineering Research Council of Canada. We thank Drs. R. Bendayan and P. Ronaldson for providing astrocyte cultures and Drs. D. M. Broussard and J. W. Wells for comments on this manuscript.

Correspondence should be addressed to Dr. David R. Hampson, Leslie Dan Faculty of Pharmacy, University of Toronto, 144 College Street, Toronto, 0N M5S 3M2, Canada. E-mail: d.hampson@utoronto.ca.

D0I:10.1523/JNEUROSCI.1081-09.2009

Copyright $\odot 2009$ Society for Neuroscience $\quad$ 0270-6474/09/298143-13\$15.00/0 brain induces excitotoxicity secondary to cellular membrane depolarization (Li and Stys, 2001; Veldhuis et al., 2003). In the CNS, it has been estimated that at least $40 \%$ of the energy delivered by respiration is required by $\mathrm{Na}, \mathrm{K}-\mathrm{ATP}$ ase to maintain ion gradients across cell membranes (Astrup et al., 1981). Thus, it is not surprising that mutations in $\mathrm{Na}, \mathrm{K}-\mathrm{ATP}$ ase genes cause a variety of abnormalities in the brain. For example, the loss of one allele through mutations in the ATP1A2 gene that encodes the $\alpha 2$ $\mathrm{Na}, \mathrm{K}-\mathrm{ATP}$ ase subunit is associated with familial hemiplegic migraine type 2 (De Fusco et al., 2003), whereas mutations in the $A T P 1 A 3$ gene coding for $\alpha 3$ subunit are associated with rapidonset dystonia parkinsonism (de Carvalho et al., 2004). Although homozygous $\alpha 2$-deficient mice die just after birth, brain tissue from embryonic day $18 \alpha 2^{-/-}$mice showed high expression of c-Fos in the amygdala and piriform cortex before the onset of apoptosis, indicative of neuronal hyperactivity. Of particular note was the observation that reuptake of glutamate and GABA into synaptosomes was impaired in these mice (Ikeda et al., 2003; Kawakami and Ikeda, 2006). Thus, it is likely that abnormalities in the CNS caused by mutations in $\mathrm{Na}, \mathrm{K}$-ATPase genes in mice and humans are attributable, in part, to altered synaptic transmission induced by impaired transmitter reuptake. Finally, the demonstration that cell surface expression and turnover of an AMPA subtype of glutamate receptor is regulated by $\mathrm{Na}, \mathrm{K}-$ ATPase activity provides additional evidence linking ATPase complexes to glutamatergic signaling (Zhang et al., 2009).

Based on the findings cited above, including the wellestablished sodium dependency of the EAATs and the observa- 
tion that GLAST and $\alpha 2 \mathrm{Na}$,K-ATPase are both highly coexpressed in cerebellar Bergmann glia (see below), we hypothesized that $\mathrm{Na}, \mathrm{K}-\mathrm{ATP}$ ase and EAATs are physically associated within a single macromolecular complex in the plasma membrane and that $\mathrm{Na}, \mathrm{K}$-ATPase is a key regulator of glutamate transporter activity. We tested this hypothesis by chromatographically copurifying the two proteins from rat cerebellum and coimmunoprecipitating the complexes from synaptosomes and transfected human embryonic kidney HEK-293T cells. In addition to colocalization experiments, we also studied the pharmacological properties and functional interactions between glutamate transporters and $\mathrm{Na}, \mathrm{K}-\mathrm{ATPase}$ in rat synaptosomes and cultured astrocytes. Our findings support this hypothesis and imply that the close coupling of the two proteins serves to regulate glutamatemediated neurotransmission.

\section{Materials and Methods}

Immunocytochemistry. For immunocytochemistry in adult Sprague Dawley rats (200-250 g), the animals were anesthetized by intraperitoneal injection of sodium pentobarbital and perfused transcardially with $0.12 \mathrm{M}$ phosphate buffer, $\mathrm{pH} 7.4$, followed by $4 \%$ paraformaldehyde in phosphate buffer. Brains were postfixed in $4 \%$ paraformaldehyde for $1 \mathrm{~h}$ and cryoprotected by infiltration with $30 \%$ sucrose in phosphate at $4^{\circ} \mathrm{C}$ overnight. After embedding in OCT compound (Sakura Finetek USA), $14-\mu \mathrm{m}$-thick sagittal sections were cut on a cryostat, mounted on poly-Llysine-coated glass slides, and air-dried overnight at $4^{\circ} \mathrm{C}$. The sections were rehydrated in $0.1 \mathrm{M}$ PBS and then incubated in blocking buffer $(0.1 \mathrm{M}$ PBS with $5 \%$ normal goat serum and containing either $0.2 \%$ Tween 20 or $0.2 \%$ Triton X-100) for $60 \mathrm{~min}$ at $25^{\circ} \mathrm{C}$. Primary antibodies were applied to the sections in a humid chamber and incubated overnight at $4^{\circ} \mathrm{C}$.

The primary antibodies used were as follows: anti- $\alpha 2 \mathrm{Na}, \mathrm{K}$-ATPase (1:200, rabbit polyclonal; Millipore Bioscience Research Reagents), antiGLAST (1:600, mouse monoclonal; Novocastra Laboratories), antiGLAST (1:200, rabbit polyclonal; Santa Cruz Biotechnology), anti- $\alpha 3$ $\mathrm{Na}, \mathrm{K}-\mathrm{ATPase}$ (1:200, clone XVIF9-G10; Novus Biologicals), antiGLT-1a (1:500, rabbit polyclonal; Affinity BioReagents), anti-GLT-1b (1:200, mouse monoclonal, clone 10B7; Abcam), and anti-glial fibrillary acidic protein (GFAP) (1:1000, mouse monoclonal, clone GA5; Millipore Bioscience Research Reagents). The secondary antisera used were as follows: goat anti-rabbit AlexaFluor 546 (diluted 1:1000; Invitrogen) or DyLight 594-conjugated AffiniPure goat anti-rabbit IgG (diluted 1:500; Jackson ImmunoResearch) and goat anti-mouse AlexaFluor 488 (diluted 1:000; Invitrogen) or DyLight 488-conjugated AffiniPure goat antimouse IgG (diluted 1:500; Jackson ImmunoResearch). The sections were then washed in PBS, coverslipped with ProLong Gold anti-fade reagent, and visualized using a Zeiss LSM 510 confocal microscope equipped with a $20 \times$ lens with a numerical aperture of 0.75 or a $40 \times$ oil immersion lens with a numerical aperture of 1.30. Control conditions included omission of primary antibodies.

Membrane preparation and solubilization of proteins from rat cerebellum. All brain membrane preparation and solubilization procedures were performed at $4^{\circ} \mathrm{C}$. Four adult rat (Sprague Dawley, 200-300 g) cerebella were homogenized in $12 \mathrm{ml}$ of buffer $(0.32 \mathrm{M}$ sucrose and $4 \mathrm{~mm}$ HEPES-NaOH, pH 7.4) on ice, using a glass Teflon homogenizer followed by centrifugation for $20 \mathrm{~min}$ at $800 \times g$. The top two layers were collected and centrifuged for $40 \mathrm{~min}$ at $48,000 \times g$; the supernatant was discarded and the pellet was resuspended in $10 \mathrm{ml} 50 \mathrm{~mm}$ Tris- $\mathrm{HCl}, \mathrm{pH}$ 7.4 , using a Polytron (setting 6, $6 \mathrm{~s}$ ). The homogenate was centrifuged at $48,000 \times g$, the supernatant was discarded, and the pellet was resuspended (using a Polytron) in $5 \mathrm{ml}$ of $50 \mathrm{~mm}$ Tris- $\mathrm{HCl}, \mathrm{pH}$ 7.4. The protein concentration of the suspension was determined using the Quanti-Pro BCA kit (Sigma), and the suspension was centrifuged for 20 $\mathrm{min}$ at $48,000 \times \mathrm{g}$. The pellet was resuspended in solubilization buffer $(50$ $\mathrm{mm}$ Tris- $\mathrm{HCl}, 10 \%$ glycerol, $1 \%$ Triton $\mathrm{X}-100,50 \mathrm{~mm} \mathrm{NaCl}$, and $1 \times$ Roche protease inhibitor cocktail, $\mathrm{pH} 7.4$ ) at a protein concentration of 2 $\mathrm{mg} / \mathrm{ml}$ using a Polytron (setting $6,4 \mathrm{~s}$ ). The suspension was incubated on ice with shaking for $1 \mathrm{~h}$, followed by centrifugation for $45 \mathrm{~min}$ at
$48,000 \times g$. The supernatant was collected and dialyzed overnight at $4^{\circ} \mathrm{C}$ in diethylaminoethyl (DEAE) dialysis buffer $(50 \mathrm{~mm}$ Tris-HCl, $50 \mathrm{~mm}$ $\mathrm{NaCl}, 0.1 \%$ glycerol, and $0.1 \%$ Triton X-100, $\mathrm{pH} 8.8$ ).

Anion exchange and ouabain affinity chromatography. All steps were performed at $4^{\circ} \mathrm{C}$, and centrifugations were performed at $150 \times g(1000$ rpm, JA-14 Beckman rotor). DEAE Sepharose Fast Flow anion exchanger (GE Healthcare) was washed and equilibrated in DEAE dialysis buffer at $\mathrm{pH}$ 8.8. The solubilized, dialyzed ( $\mathrm{pH}$ 8.8) sample was added to DEAE Sepharose at a ratio of $1: 1(\mathrm{v} / \mathrm{v})$ and incubated for $1 \mathrm{~h}$, the DEAE beads were washed with 20 bed volumes of dialysis buffer, and fractions were eluted as follows: elution 1 ( $6 \mathrm{ml}, 50 \mathrm{~mm}$ Tris- $\mathrm{HCl}, 50 \mathrm{~mm} \mathrm{NaCl}, 0.1 \%$ glycerol, $0.1 \%$ Triton X-100, and $1 \mathrm{~mm} \mathrm{CaCl}_{2}, \mathrm{pH} 7.0$ ) was added to the DEAE beads and incubated for $30 \mathrm{~min}$; the eluant was collected and the beads were subjected to elution 2 using the same buffer as above except the $\mathrm{pH}$ was 5.5. The supernatant from the $\mathrm{pH} 5.5$ fraction was collected and dialyzed for $15 \mathrm{~h} \mathrm{in} \mathrm{K}^{+}$loading buffer $(60 \mathrm{~mm} \mathrm{KCl}, 25 \mathrm{~mm}$ imidazole, $1 \mathrm{~mm}$ EDTA, $1 \mathrm{~mm} \mathrm{CaCl}_{2}$, and $0.1 \%$ Triton X-100, $\mathrm{pH}$ 7.4) for subsequent purification on the ouabain affinity matrix.

The ouabain affinity matrix was prepared according to a previously described procedure (Yingst et al., 1998). One gram g of epoxy-activated agarose (Sigma) with a 12 atom spacer was added to $15 \mathrm{ml}$ of a solution containing 10 or $20 \mathrm{~mm}$ ouabain and $100 \mathrm{~mm}$ sodium carbonate, $\mathrm{pH} 8.5$, at room temperature. The mixture was then incubated at $37^{\circ} \mathrm{C}$ for $20 \mathrm{~h}$, after which the beads were washed with $10 \mathrm{ml}$ of $100 \mathrm{~mm}$ sodium carbonate buffer, $\mathrm{pH} 8.5$, followed by $10 \mathrm{ml}$ of water. The beads were incubated with $1 \mathrm{M}$ ethanolamine, $\mathrm{pH} 8.5$, for $4 \mathrm{~h}$ at $37^{\circ} \mathrm{C}$ to block unreacted coupling sites. The column was washed with $200 \mathrm{~mm}$ Tris- $\mathrm{HCl}, \mathrm{pH} 8.5$, and stored in 50 mm imidazole containing $\mathrm{NaN}_{3}, \mathrm{pH}$ 7.4. Before purification, the ouabain affinity column (containing $7.5 \mathrm{ml}$ of beads) was washed with 50 bed volumes of $50 \mathrm{~mm}$ imidazole, $\mathrm{pH} 7.4$, and equilibrated with two bed volumes of $\mathrm{K}^{+}$loading buffer. A mock elution was performed with $10 \mathrm{ml}$ of elution buffer ( $10 \mathrm{~mm}$ ouabain, $25 \mathrm{~mm}$ imidazole, $150 \mathrm{~mm}$ $\mathrm{NaCl}$, and $1 \times$ protease inhibitor cocktail, $\mathrm{pH} 7.4$ ), followed by a wash with 4 bed volumes of $\mathrm{K}^{+}$loading buffer. The DEAE, $\mathrm{pH} 5.5$, eluate (6 $\mathrm{ml}$, dialyzed in $\mathrm{K}^{+}$loading buffer overnight) was incubated with the ouabain affinity matrix for $1 \mathrm{~h}$ at $4^{\circ} \mathrm{C}$; after $1 \mathrm{~h}$, the column was mounted vertically and drained from the bottom under gravity at $4^{\circ} \mathrm{C}$ collecting the immediate flow through until there was no buffer left standing above the column (ouabain unretained fraction). The column was then washed at $4^{\circ} \mathrm{C}$ with 3 bed volumes of $\mathrm{K}^{+}$loading buffer $(20 \mathrm{ml})$. The column was mounted vertically, and the final $1 \mathrm{ml}$ of $\mathrm{K}^{+}$loading buffer was collected (last wash). Elution buffer $(5 \mathrm{ml})$ was then added, the column was rocked at $4^{\circ} \mathrm{C}$ for $30 \mathrm{~min}$, and the elution buffer was collected (elution fraction 1); three additional elutions of $5 \mathrm{ml}$ each with the same elution buffer were conducted (most of the Na,K-ATPase protein eluted in the first $5 \mathrm{ml}$ fraction). The fractions were analyzed by Western blotting. Elution fraction 1 was also analyzed by mass spectrometry (see below).

Western blotting. Gel electrophoresis was performed on 6 or $10 \%$ polyacrylamide gels. After transferring the proteins to nitrocellulose, the blots were incubated in blocking buffer $(0.01 \mathrm{M}$ Tris- $\mathrm{HCl}, 0.15 \mathrm{M} \mathrm{NaCl}, 0.2 \%$ Tween 20 , and $5 \%$ w/v nonfat dry milk, $\mathrm{pH} 8.0$ ) overnight at $4^{\circ} \mathrm{C}$. The blots were then washed three times with wash buffer $(0.01 \mathrm{M}$ Tris-HCl, $0.15 \mathrm{M} \mathrm{NaCl}$, and $0.2 \%$ Tween $20, \mathrm{pH} 8.0$ ) at room temperature, followed by incubation for $2 \mathrm{~h}$ with the primary antibodies as follows: anti-GLAST [1:1000, rabbit polyclonal (Santa Cruz Biotechnology) or 1:500, mouse monoclonal antibody (Novocastra Laboratories)], anti-GLT-1 [1:2000, rabbit polyclonal raised against the sequence N(556)GKSADCSVEEEPWKREK(573) of rat GLT-1 (Affinity BioReagents)], nonselective anti- $\alpha \mathrm{Na}, \mathrm{K}$-ATPase (1:2000, mouse monoclonal; Affinity BioReagents), anti- $\alpha 1 \mathrm{Na}, \mathrm{K}-\mathrm{ATPase}$ (6F, 1:500, mouse monoclonal raised against N-terminal amino acids 27-55; University of Iowa, Iowa City, IA), anti- $\alpha 2 \mathrm{Na}$,K-ATPase (1:2000, rabbit polyclonal; Millipore Bioscience Research Reagents), anti- $\alpha 3 \mathrm{Na}, \mathrm{K}-\mathrm{ATPase}$ (1:2000, mouse monoclonal clone XVIF9-G10; Affinity BioReagents), anti- $\beta 2 \mathrm{Na}, \mathrm{K}-\mathrm{ATPase}$ (1:1000, mouse monoclonal clone 35; BD Biosciences), and anti-c-myc (1:1000, mouse monoclonal clone 9E10 raised against amino acids $408-437$ of the leucine zipper region of human Myc; Millipore). After incubation with primary antibodies, the blots were washed three times in wash buffer, incubated with secondary antibodies including HRP-conjugated 
goat anti-rabbit IgG antibody (1:30,000; Pierce) or HRP-conjugated donkey anti-mouse IgG (1:2500; Jackson ImmunoResearch) for $2 \mathrm{~h}$, washed three times in wash buffer, followed by detection with ECL Western blotting detection kit (GE Healthcare) or SuperSignal West Pico Chemiluminescent Substrate (Thermo Fisher Scientific).

Protein identification by mass spectrometry. The eluate obtained after DEAE anion exchange/ouabain affinity purification ( $\sim 50 \mu \mathrm{g}$ of protein) was precipitated with $25 \%$ trichloroacetic acid (final concentration) on ice for $30 \mathrm{~min}$ and centrifuged for $30 \mathrm{~min}$ at $12,000 \times \mathrm{g}$ at $4^{\circ} \mathrm{C}$, and the pellet was washed twice with cold acetone $\left(-20^{\circ} \mathrm{C}\right)$ containing $0.05 \mathrm{~N}$ $\mathrm{HCl}$ and centrifuged for $5 \mathrm{~min}$ at $12,000 \times \mathrm{g}$ at $4^{\circ} \mathrm{C}$. The supernatant was removed and the sample was dried at room temperature for $15 \mathrm{~min}$. The proteins were then reduced in $25 \mathrm{~mm}$ dithiothreitol, alkylated using 100 mM iodoacetamide, and brought to $1 \mathrm{mM} \mathrm{CaCl}_{2}$. The sample was trypsinized by the addition of sequence grade trypsin ( $1 \mu \mathrm{g}$; Promega) and incubated at $37^{\circ} \mathrm{C}$ for $16 \mathrm{~h}$. The digested sample $(25 \mu \mathrm{l})$ was pressure loaded onto a fused silica microcapillary column packed in-house with C-12 reverse-phase Jupiter material (Phenomenex). The peptides were eluted from the HPLC column by progressively increasing the concentration of the organic solvent $\left(95 \%\right.$ acetonitrile, $5 \% \mathrm{H}_{2} \mathrm{O}$, and $0.1 \%$ trifluoroacetic acid) and then subjected to electrospray ionization and analyzed by an LTQ-XL ion-trap mass spectrometer (Thermo Fisher Scientific). Peptide ions were dynamically selected using data-dependent acquisition by the operating software for fragmentation. The peptide fragmentation spectra were searched against the National Center for Biotechnology Information nonredundant protein database using the SEQUEST computer algorithm on the Sorcerer platform (SageNResearch).

Synaptosome preparation. Synaptosomes were isolated from adult rat forebrain or cerebellum (200 g male Sprague Dawley) according to a previously described protocol (Huttner et al., 1983). All steps were performed at $4^{\circ} \mathrm{C}$. Briefly, one rat forebrain was homogenized in $7 \mathrm{ml}$ of ice-cold buffer ( $0.32 \mathrm{~m}$ sucrose and $4 \mathrm{~mm}$ HEPES-NaOH, pH 7.4) using a glass Teflon homogenizer (five to six strokes at $500 \mathrm{rpm}$ ). The homogenate was centrifuged for $10 \mathrm{~min}$ at $800 \times \mathrm{g}$. The pellet was discarded, and the top two layers were collected and centrifuged for $15 \mathrm{~min}$ at $9200 \times \mathrm{g}$. The supernatant was discarded, and the P2 pellet was resuspended in 35 $\mathrm{ml}$ of ice-cold buffer and subjected to $15 \mathrm{~min}$ centrifugation at 10,200 $\times$ $g$. The resultant pellet (P3, crude synaptosome fraction) was resuspended in $1 \mathrm{ml}$ of buffer, and the protein concentration was measured using the Quanti-Pro BCA kit (Sigma).

Primary cultures of rat astrocytes. Primary cultures of rat astrocytes were prepared as described previously (Ronaldson et al., 2004). All procedures were performed in accordance with the University of Toronto Animal Care Committee and the Province of Ontario Animals for Research Act. Briefly, neonatal (2 d old) Wistar rats (Charles River Laboratories) were killed by cervical dislocation, and the whole brains were isolated. Cerebral cortices were then dissected and subjected to enzymatic digestion for $30 \mathrm{~min}$ in serum-free minimum essential medium containing $2.0 \mathrm{mg} / \mathrm{ml}$ porcine pancreatic trypsin (Sigma-Aldrich) and $0.005 \%$ DNaseI. The tissue was then mechanically disaggregated to yield a mixed glial cell suspension. Mixed glial cell suspensions were centrifuged $(10 \mathrm{~min}, 100 \times \mathrm{g})$ and resuspended in fresh culture medium consisting of minimum essential medium supplemented with $5 \%$ horse serum, $5 \%$ fetal bovine serum, and $50 \mu \mathrm{g} / \mathrm{ml}$ gentamicin. The cells were incubated in fresh medium at $37^{\circ} \mathrm{C}, 5 \% \mathrm{CO}_{2}$ and $95 \%$ air overnight for $10-12 \mathrm{~d}$, after which they were placed on an orbital shaker at $100 \mathrm{rpm}$ for $2 \mathrm{~h}$ to remove contaminating oligodendrocytes, microglia, and neurons. The cultures were grown for an additional 1-3 d (total of 10-14 d in vitro) before Western blot or D-aspartate uptake analyses.

Rubidium-86 uptake into synaptosomes. Rubidium-86 uptake into synaptosomes to measure the potassium ion pumping activity of $\mathrm{Na}, \mathrm{K}$ ATPase was performed according to a previously described protocol (Fraser and Arieff, 2001). To preload the synaptosomes with sodium, the pellet was resuspended in $4 \mathrm{ml}$ of preequilibration buffer [in mM: 150 $\mathrm{NaCl}, 1 \mathrm{MgCl}_{2}$, and 53 -( $\mathrm{N}$-morpholino)-propanesulfonic acid (MOPS)Tris, $\mathrm{pH} 7.4$ ], incubated for $10 \mathrm{~min}$ at $37^{\circ} \mathrm{C}$, and centrifuged for $5 \mathrm{~min}$ at $20,000 \times g$ (Beckman Coulter JA-20 rotor). The synaptosomes were diluted to a protein concentration of $10 \mathrm{mg} / \mathrm{ml}$ in preequilibration buffer. To commence uptake, $0.5 \mu$ Ci of rubidium-86 (PerkinElmer Life and Analytical Sciences) was added to $5 \mu \mathrm{l}$ of $10 \mathrm{mg} / \mathrm{ml}$ synaptosome suspension, $10 \mu \mathrm{l}$ of a $10 \times$ stock solution of ouabain, and external media (in mM: 140 choline chloride, $5 \mathrm{MgCl}_{2}, 0.2 \mathrm{EGTA}, 1 \mathrm{KCl}$, and $5 \mathrm{~mm}$ MOPS-KOH, pH7.4) to a final volume of $100 \mu \mathrm{l}$, and the reaction was allowed to proceed for $5 \mathrm{~min}$ at $25^{\circ} \mathrm{C}$; the reaction was stopped by adding $2 \mathrm{ml}$ of cold $150 \mathrm{~mm}$ choline chloride, followed by filtration through Millipore HAWP filters $(25 \mathrm{~mm}, 0.4 \mu \mathrm{M})$. The filters were washed twice with $2 \mathrm{ml}$ of cold $150 \mathrm{~mm}$ choline chloride and counted on a liquid scintillation counter. Controls were performed in the absence of ouabain.

Glutamate transporter assays. [ $\left.{ }^{3} \mathrm{H}\right]_{\mathrm{D}}$-aspartate or $\left[{ }^{3} \mathrm{H}\right]_{\mathrm{L}}$-glutamate uptake assays into synaptosomes were performed according to a previously described protocol (Fremeau et al., 2001). The crude synaptosomes were diluted to a protein concentration of $0.2 \mathrm{mg} / \mathrm{ml}$ in assay buffer (in mM: 10 Tris-acetate, $128 \mathrm{NaCl}, 10$ D-glucose, $5 \mathrm{KCl}, 1.5 \mathrm{NaH}_{2} \mathrm{PO}_{4}, 1 \mathrm{MgSO}_{4}$, and $1 \mathrm{CaCl}_{2}, \mathrm{pH}$ 7.4). A preincubation was performed with or without inhibitors [final concentrations: $10 \mu \mathrm{M} \quad \mathrm{H} 89$ ( $N$-[2-( $p$-bromocinnamylamino)-ethyl]-5-isoquinoline-sulfon-amide $2 \mathrm{HCl}), 10 \mu \mathrm{M}$ staurosporine, $1 \mu \mathrm{M}$ wortmannin, $100 \mathrm{nM}$ PP2 (4-amino-5-(4chlorophenyl)-7-( $t$-butyl)pyrazolo[3,4- $d$ ] pyrimidine), $1 \mu \mathrm{M}$ SU6656, or $0.1 \%$ DMSO as a vehicle control] at $25^{\circ} \mathrm{C}$ for $30 \mathrm{~min}$, followed by a $5 \mathrm{~min}$ incubation with buffer only or with $200 \mu \mathrm{M}$ DL-threo- $\beta$-benzyloxy aspartic acid (TBOA), $200 \mu \mathrm{M}$ dihydrokainate (DHK), $1 \mu \mathrm{M}$ WAY213613 [N(4)-[4-(2-bromo-4, 5-difluorophenoxy)phenyl]-L-asparagine], and 1 $\mu \mathrm{M}$ to $1 \mathrm{~mm}$ ouabain when indicated. To commence uptake, $1 \mu \mathrm{M}\left[{ }^{3} \mathrm{H}\right]_{\mathrm{D}}$ aspartate $(23.9 \mathrm{Ci} / \mathrm{mmol}$; PerkinElmer Life and Analytical Sciences) and $49 \mu \mathrm{M}$ unlabeled $\mathrm{D}$-aspartate were added, and the reaction was allowed to proceed for $2 \mathrm{~min}$ at $25^{\circ} \mathrm{C}$; the reaction was stopped by adding $4 \mathrm{ml}$ of cold buffer, followed by filtration through HAWP filters $(25 \mathrm{~mm}, 0.4$ $\mu \mathrm{m}$; Millipore) and washed once with $4 \mathrm{ml}$ of cold buffer. In some experiments, $99 \mu \mathrm{M}$ unlabeled L-glutamate plus $1 \mu \mathrm{M}\left[{ }^{3} \mathrm{H}\right] \mathrm{L}$-glutamate (49 $\mathrm{Ci} / \mathrm{mmol}$; PerkinElmer Life and Analytical Sciences) was used instead of $\left[{ }^{3} \mathrm{H}\right] \mathrm{D}$-aspartate. Negative controls contained synaptosomes suspended in sodium-free buffer (128 mm choline chloride and $1.5 \mathrm{~mm} \mathrm{KH}_{2} \mathrm{PO}_{4}$ substituted for $128 \mathrm{~mm} \mathrm{NaCl}$ and $1.5 \mathrm{~mm} \mathrm{NaH}_{2} \mathrm{PO}_{4}$, respectively). All results were adjusted for background by subtracting counts obtained from samples excluding protein (synaptosomes) from the assay.

For experiments in cultured astrocytes, the cells were washed once with assay buffer (in mM: $138 \mathrm{NaCl}, 11 \mathrm{D}$-glucose, $5.3 \mathrm{KCl}, 0.4 \mathrm{KH}_{2} \mathrm{PO}_{4}$, $0.3 \mathrm{Na}_{2} \mathrm{HPO}_{4}, 0.7 \mathrm{MgSO}_{4}, 1.1 \mathrm{CaCl}_{2}$, and 10 HEPES-NaOH, pH 7.4) and incubated in assay buffer with or without glutamate transporter inhibitors $200 \mu \mathrm{M}$ TBOA, $200 \mu \mathrm{M}$ DHK, $1 \mu \mathrm{M}$ WAY213613, or $1 \mu \mathrm{M}$ to $1 \mathrm{~mm}$ ouabain at $37^{\circ} \mathrm{C}$ for $5 \mathrm{~min}$. To commence uptake, $1 \mu \mathrm{M}\left[{ }^{3} \mathrm{H}\right]_{\mathrm{D}}$-aspartate and $49 \mu \mathrm{M}$ unlabeled D-aspartate were then added and incubated for 5 $\min$ at $37^{\circ} \mathrm{C}$, after which the reaction was stopped by suctioning off the buffer and washing three times with $0.5 \mathrm{ml}$ of ice-cold assay buffer per well. The samples were dissolved in $500 \mu \mathrm{l}$ of $0.4 \mathrm{~N} \mathrm{NaOH}$ and analyzed via liquid scintillation counting. Negative controls were incubated in sodium-free buffer ( $138 \mathrm{~mm}$ choline chloride and $0.3 \mathrm{~mm} \mathrm{~K}_{2} \mathrm{HPO}_{4}$ substituted for $138 \mathrm{~mm} \mathrm{NaCl}$ and $0.3 \mathrm{mM} \mathrm{Na}_{2} \mathrm{HPO}_{4}$, respectively). All results are expressed as the mean \pm SEM of $n$ experiments of the percentage of the sodium-containing control. Statistical analyses were performed using one-way ANOVA, followed by Dunnett's test when comparing test conditions with the positive control or by Bonferroni's test when comparing between conditions.

Immunoprecipitations. For immunoprecipitations with $\alpha 2$ and $\alpha 3$ and probing for GLT-1, synaptosomes were prepared from rat forebrain or cerebellum as described above and resuspended in solubilization buffer (50 mu Tris- $\mathrm{HCl}, 150 \mathrm{~mm} \mathrm{NaCl}, 1 \mathrm{~mm} \mathrm{NaH}{ }_{2} \mathrm{PO}_{4} \cdot 7 \mathrm{H}_{2} \mathrm{O}, 1 \% \mathrm{NP}-40,1 \mathrm{~mm}$ $\mathrm{CaCl}_{2}$, and $1 \times$ Roche protease inhibitor cocktail, $\mathrm{pH}$ 7.5) at a concentration of $1 \mathrm{mg} / \mathrm{ml}$ total protein. The suspension was then incubated on ice for $1 \mathrm{~h}$, followed by centrifugation for $45 \mathrm{~min}$ at $4^{\circ} \mathrm{C}, 48,000 \times g$. The resulting supernatant (solubilized synaptosome preparation), was used for immunoprecipitation. Protein A- and G-agarose beads (1:1 slurry; Sigma) were washed with PBS and restored as a $50 \%$ slurry; to preclear the samples, the solubilized synaptosome samples were added to $15 \mu \mathrm{l}$ of the protein $A+G$ slurry and incubated for $30 \mathrm{~min}$ at $4^{\circ} \mathrm{C}$. The samples were then centrifuged at $14,000 \times g$ for $5 \mathrm{~min}$, and the supernatant was transferred to a new microcentrifuge tube with $2 \mu \mathrm{l}$ of anti- $\alpha 3 \mathrm{Na}, \mathrm{K}$ - 
ATPase mouse monoclonal antibody (Affinity BioReagents) or $2 \mu \mathrm{l}$ of anti- $\alpha 2 \mathrm{Na}$,K-ATPase rabbit polyclonal antibody (Millipore Bioscience Research Reagents) and incubated for $1 \mathrm{~h}$, rocking, at $4^{\circ} \mathrm{C}$. Separately, protein $\mathrm{A}+\mathrm{G}$ agarose beads were incubated in $1 \mathrm{mg} / \mathrm{ml}$ bovine serum albumin solution for $1 \mathrm{~h}$, washed, and equilibrated in wash buffer $(20 \mathrm{~mm}$ Tris$\mathrm{HCl}, 0.1 \%$ TX-100, $1 \%$ glycerol, $100 \mathrm{~mm} \mathrm{NaCl}$, and $1 \mathrm{~mm} \mathrm{CaCl}_{2}, \mathrm{pH} 7.5$ ) to make a $50 \%$ slurry. After incubating for $1 \mathrm{~h}$ with the antibody, $50 \mu \mathrm{l}$ of preblocked protein $A+G$ beads were added to the samples and incubated overnight on a rocker at $4^{\circ} \mathrm{C}$. The agarose beads were collected by centrifugation and washed three times in wash buffer, and the beads were resuspended in $40 \mu$ l of $2 \times$ sample buffer ( $4 \%$ SDS, $63 \mathrm{~mm}$ Tris, and $10 \%$ glycerol) and $100 \mathrm{~mm}$ DTT and incubated for $3 \mathrm{~min}$ at $100^{\circ} \mathrm{C}$ to elute immunoprecipitated proteins. The eluates were subjected to SDS-PAGE and Western blotting. For the immunoprecipitation with $\alpha 2$ probing for GLAST, the starting material was crude solubilized membranes from rat cerebellum prepared as described above (see Membrane preparation and solubilization of proteins from rat cerebellum) except that the solubilized cerebellum was dialyzed against DEAE dialysis buffer, $\mathrm{pH}$ 7.4. The subsequent procedures for immunoprecipitation were performed as described above.

For immunoprecipitations in HEK-293T cells (American Type Culture Collection), the cells were mock transfected or cotransfected with $2.5 \mu \mathrm{g}$ of wild-type rat $\alpha 2 \mathrm{Na}$,K-ATPase cDNA in the pcDNA3.0 vector (kindly provided by Drs. V. Canfield and R. Levenson, Penn State College, Hershey, PA) (Canfield and Levenson, 1998) plus $1 \mu \mathrm{g}$ of the rat $\beta 2 \mathrm{cDNA}$ (kindly provided by Dr. P. Martin-Vasallo, Universidad de La Laguna, Tenerife, Spain) and $2.5 \mu \mathrm{g}$ of rat GLAST cDNA in pcDNA3.1A (kindly provided by Dr. M. Robinson, University of Pennsylvania, Philadelphia, PA) (Susarla et al., 2004) in a $10 \mathrm{~cm}$ dish using Lipofectamine 2000. Forty eight hours after transfection, the cells were collected, solubilized, and subjected to immunoprecipitation as described above.

\section{Results}

Colocalization of glutamate transporters with Na,K-ATPase $\alpha$ subunits in rat brain

As a first step toward testing the hypothesis that EAATs and $\mathrm{Na}, \mathrm{K}-\mathrm{ATP}$ ases are components of the same protein complexes, we compared the distributions of GLAST and $\alpha 2 \mathrm{Na}, \mathrm{K}$-ATPase mRNAs in mouse brain as reported in the Allen Brain Atlas (http://www.brain-map.org/). In the mouse cerebellum, the two mRNAs displayed a similarly prominent expression pattern that tracked the Purkinje cell layer in the cerebellar cortex (Fig. $1 H, I$ ). The Purkinje cell layer contains the cell bodies of Purkinje neurons and the Bergmann glia whose cell bodies are also in and adjacent to this cellular layer.

To investigate whether the $\alpha 2 \mathrm{Na}, \mathrm{K}-\mathrm{ATP}$ ase and GLAST colocalize to the same cells, immunocytochemical analyses were performed on sagittal sections of adult rat cerebellar cortex. $\alpha 2$ $\mathrm{Na}, \mathrm{K}-\mathrm{ATP}$ ase immunoreactivity was observed in Purkinje cells and showed diffuse staining in the granule layer (Fig. $1 A$ ). These results are in agreement with a previous study on the distribution of $\alpha 2 \mathrm{Na}, \mathrm{K}-\mathrm{ATP}$ ase in the cerebellum (Peng et al., 1997). We also
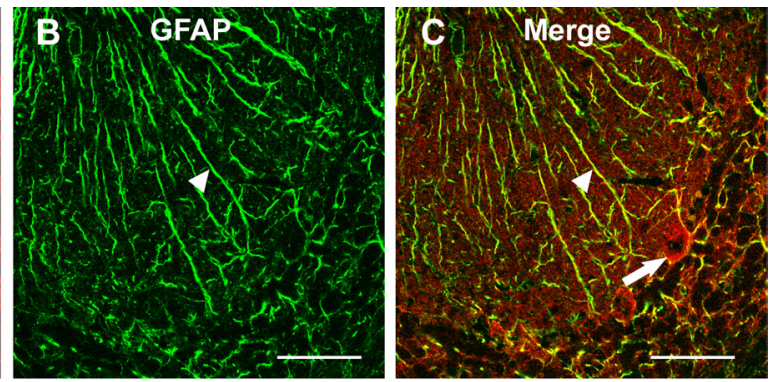
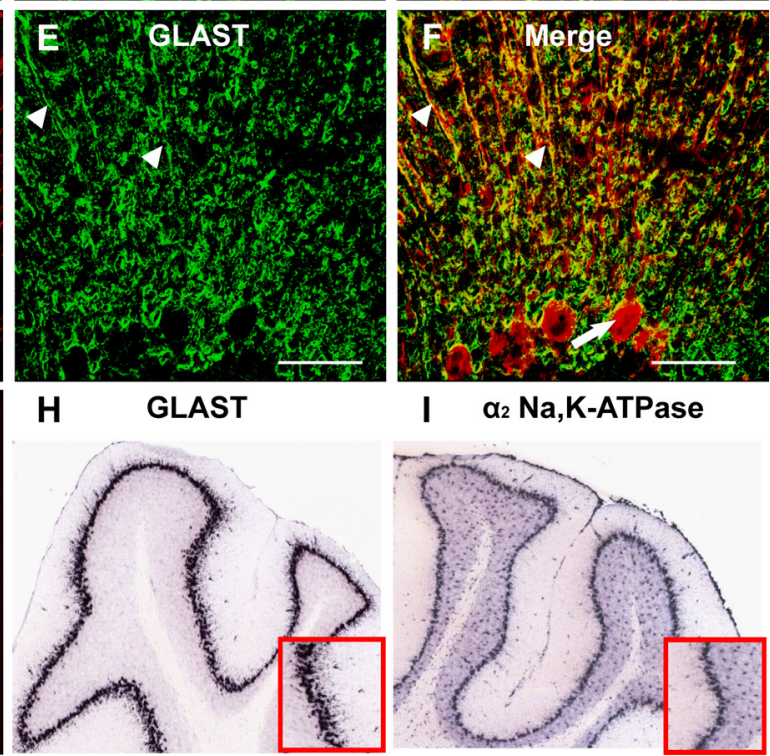

I $\alpha_{2} \mathrm{Na}, \mathrm{K}-\mathrm{ATP}$ ase

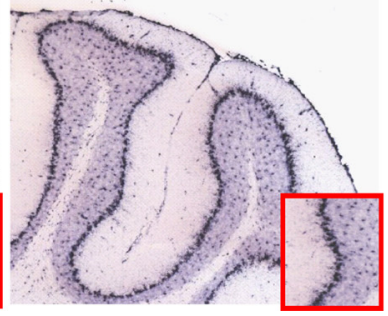

H GLAST

Figure 1. Colocalization of GLAST and GFAP with $\alpha 2 \mathrm{Na}$, K-ATPase in the rat cerebellar cortex. A, Immunocytochemical distribution of $\alpha 2 \mathrm{Na}$,K-ATPase in Bergmann glia processes (arrowhead) and Purkinje cell bodies (arrow) in the cerebellar cortex. $B, C$ 政 antibody; $\boldsymbol{E}$ ) in the Bergmann glia processes (arrowheads) is depicted in the merged image shown in $F$. G, Negative control with no primary antibody. $\boldsymbol{H}, \boldsymbol{I}$, In situ hybridization analysis of GLAST $(\boldsymbol{H})$ and $\alpha 2$ Na,K-ATPase mRNA $(\boldsymbol{I})$ in the mouse cerebellum (from the Allen Brain Atlas). GL, Granule cell layer; ML, molecular layer; PL, Purkinje cell layer of the cerebellar cortex. Scale bars, $50 \mu \mathrm{m}$.

observed that $\alpha 2 \mathrm{Na}, \mathrm{K}$-ATPase is present in the Bergmann glial processes and colocalizes with the glial marker GFAP (Fig. $1 B, C$ ). Using a monoclonal antibody, prominent expression of GLAST was seen in the molecular layer of the cerebellar cortex, including the processes of the Bergmann glia (Fig. $1 E$ ) in which it colocalized with $\alpha 2 \mathrm{Na}, \mathrm{K}$-ATPase (Fig. $1 F$ ). Immunostaining for GLAST was also observed in the granule cell layer. Glutamate transporter expression in the cerebellum is known to vary among different mammalian species. Unlike other species such as mice (Takayasu et al., 2005; Williams et al., 2005) and primates (Williams et al., 2005) in which GLAST expression is restricted to the Bergmann glia, in the rat cerebellum GLAST protein expression is present not only in the Bergmann glia but also in the granule cell layer (Chaudhry et al., 1995; Williams et al., 2005). Together, the results depicted in Figure 1 show that GLAST and $\alpha 2 \mathrm{Na}, \mathrm{K}$ ATPase are coexpressed in the Bergmann glia of the cerebellar cortex.

Colocalization of GLT- 1 with $\alpha 2$ and $\alpha 3 \mathrm{Na}, \mathrm{K}-\mathrm{ATP}$ ase subunits was examined in the CA1 region of the rat hippocampus. Two different GLT-1 antibodies were used; a mouse monoclonal antibody that recognizes the GLT-1b splice form was paired with the rabbit anti- $\alpha 2 \mathrm{Na}, \mathrm{K}-\mathrm{ATP}$ ase antibody, and a rabbit polyclonal antibody that recognizes the GLT-1a splice variant was paired with the anti- $\alpha 3 \mathrm{Na}, \mathrm{K}$-ATPase mouse monoclonal antibody (for locations of GLT-1 antibody epitopes, see supplemen- 

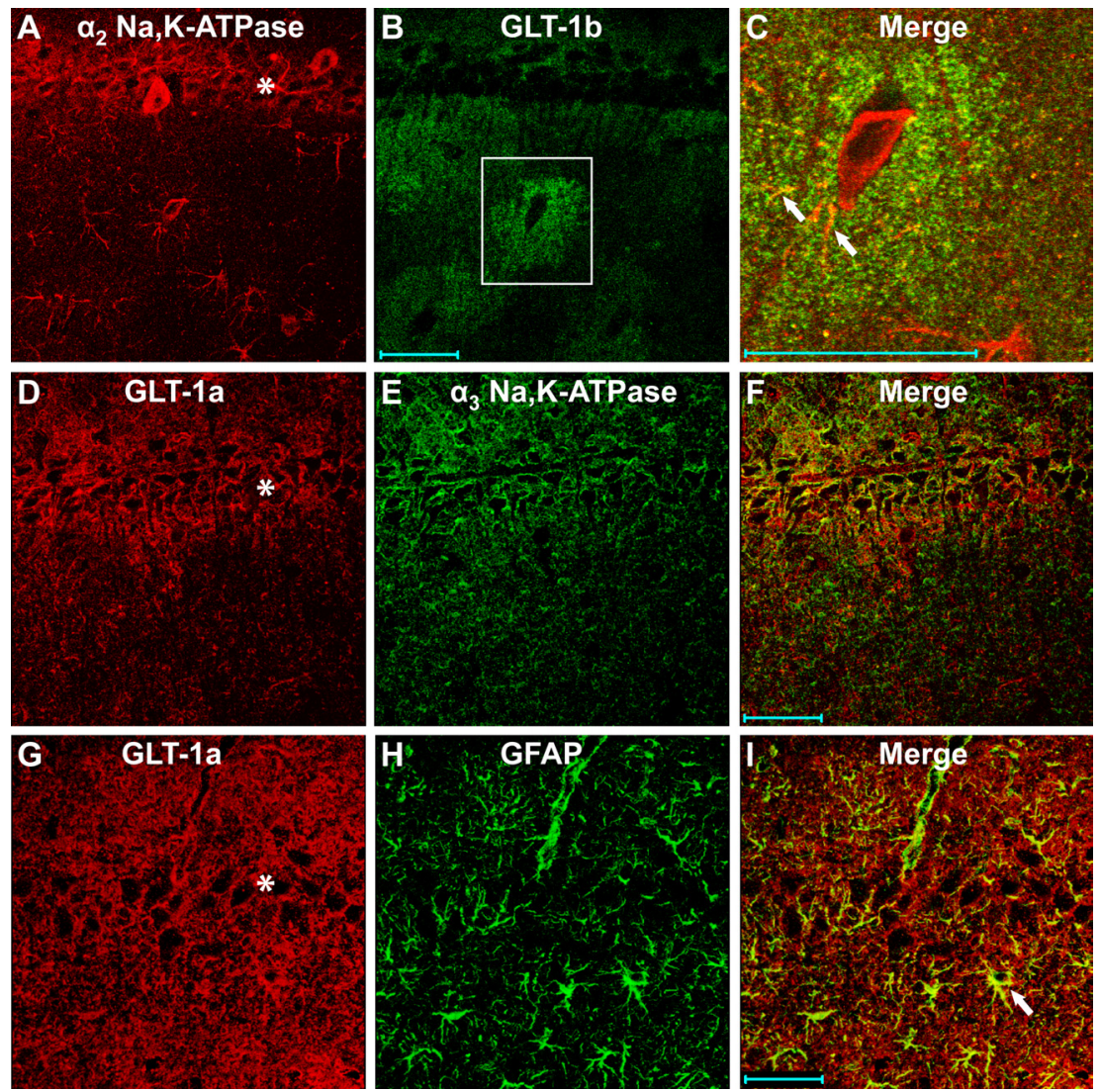

Figure 2. Colocalization of $\alpha 2$ and $\alpha 3 \mathrm{Na}$,K-ATPase with GLT-1 in the CA1 region of the rat hippocampus. $\boldsymbol{A}$, Immunocytochemical distribution of $\alpha 2 \mathrm{Na}$,K-ATPase visualized with a tetramethylrhodamine isothiocyanate-conjugated anti-rabbit secondary. $\boldsymbol{B}, \boldsymbol{C}$, GLT-1b expression visualized with FITC-conjugated anti-mouse secondary antibody $(\boldsymbol{B})$ and merged portion of images of $\boldsymbol{A}$ and $\boldsymbol{B}$ within boxed region indicated in $\boldsymbol{B}(\boldsymbol{C})$ showing colocalization in astrocyte processes (arrows). $\boldsymbol{D}-\boldsymbol{F}$, The colocalization of GLT-1a (rabbit polyclonal; $\boldsymbol{D}$ ) with $\alpha 3 \mathrm{Na}$,K-ATPase (mouse monoclonal; $\boldsymbol{E}$ ) primarily in the pyramidal cell layer is depicted in the merged image shown in $\boldsymbol{F}$. $\mathbf{G}-\boldsymbol{I}$, The colocalization of GLT-1a $(\boldsymbol{G})$ and the astrocyte marker GFAP (mouse monoclonal; $\boldsymbol{H}$ ) is shown in the merged image in I (example indicated by arrow). Asterisks indicate pyramidal cell layer. Scale bars, $50 \mu \mathrm{m}$.
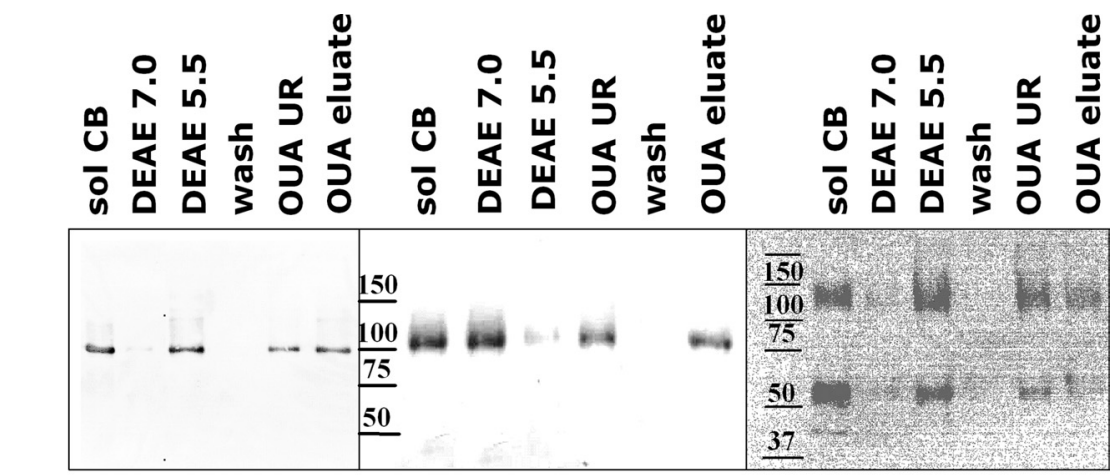

\section{WB: non-selective $\alpha$ NKA \\ $\alpha_{2}$ Na,K-ATPase}

Figure 3. Copurification of GLAST and $\alpha \mathrm{Na}$,K-ATPase from adult rat cerebellum by tandem DEAE anion exchange and ouabain affinity chromatography. Chromatography fractions were analyzed on Western blots (WB) probed with a nonselective $\alpha$ Na,KATPase (NKA) antibody (left), an $\alpha 2$ Na,K-ATPase-specific antibody (middle), and a GLAST antibody (right). $\boldsymbol{A}-\boldsymbol{C}$, The $\alpha$ subunits of Na,K-ATPase (seen at $100 \mathrm{kDa}$ in $\boldsymbol{A}, \boldsymbol{B})$ and the monomeric and dimeric forms of GLAST seen at 65 and $130 \mathrm{kDa}(\boldsymbol{C}$ ) were detected in the final eluate from the ouabain affinity column (OUA eluate). Sol CB, Crude solubilized cerebellar membranes; OUA UR, unretained fraction from ouabain affinity column.

tal Figure S2, available at www.jneurosci.org as supplemental material). Thus, the combination of anti-GLT1b with $\alpha 3 \mathrm{Na}, \mathrm{K}-$ ATPase was precluded because both were mouse monoclonal antibodies, and, likewise, the combination of GLT-1a with $\alpha 2$
GLAST

$\mathrm{Na}, \mathrm{K}-\mathrm{ATP}$ ase was precluded because both were rabbit polyclonals. GLT-1b immunostaining was absent from the pyramidal cell body layer but showed a diffuse "cloudy" staining pattern corresponding to astrocytic processes outside this layer (Fig. 2B), as described previously by Reye et al. (2002). GLT-1b displayed some, albeit limited, colocalization with $\alpha 2 \mathrm{Na}, \mathrm{K}$ ATPase in presumably astrocytic processes (Fig. 2C). The pattern of immunostaining for GLT-1a was different from that seen for GLT-1b; GLT-1a showed more widespread labeling of which only a portion colabeled with the astrocytic marker GFAP (Fig. 2G-I). GLT-1a colocalized with $\alpha 3$ $\mathrm{Na}, \mathrm{K}-\mathrm{ATP}$ ase both within and outside of the pyramidal cell layer, and both proteins also showed regions of nonoverlapping expression (Fig. $2 D-F$ ). Together, these results indicate that, in the hippocampus, GLT-1b showed some limited colocalization with the glial $\alpha 2 \mathrm{Na}$,K-ATPase subunit and that the more heavily expressed GLT-1a isoform partially colocalizes with the neuronally expressed $\alpha 3 \mathrm{Na}$,K-ATPase subunit.

Glutamate transporters copurify and coimmunoprecipitate with $\mathrm{Na}, \mathrm{K}$ -

ATPase in rat brain

We next sought to ascertain whether GLAST and $\alpha 2 \mathrm{Na}, \mathrm{K}$-ATPase copurify in extracts from the cerebellum. Rat cerebellar membranes were solubilized, and the solubilized material was subjected to purification using DEAE anion exchange chromatography. Western blot analysis indicated that both GLAST and Na,K-ATPase $\alpha$ subunits eluted in the $\mathrm{pH} 5.5$ fraction (Fig. 3). The pH 5.5 fraction was then dialyzed and applied to an ouabain affinity column, the column was washed, and the bound ATPases were eluted with a buffer containing sodium and a high concentration of ouabain. Western blot analysis of the ouabain affinity eluate using an antibody to GLAST and two antibodies to $\mathrm{Na}, \mathrm{K}$-ATPase $\alpha$ subunits showed the presence of GLAST and $\alpha 2 \mathrm{Na}, \mathrm{K}$-ATPase. The bands for GLAST and Na,K-ATPase subunits in the unretained fraction from the ouabain column indicated that the capacity of the column may have been exceeded. Mass spectrometry performed on the ouabain-eluted fraction (fraction 1) confirmed the presence of GLAST and $\alpha 2$ $\mathrm{Na}, \mathrm{K}-\mathrm{ATP}$ ase $(n=3)$. In addition, GLT- 1 and $\alpha 1$ and $\alpha 3 \mathrm{Na}, \mathrm{K}-\mathrm{ATP}$ ase subunits were also unequivocally identified by the fragmentation patterns (tandem mass spectrometry of the trypsin-generated peptides) from the mass spectrometer (see supplemental Figs. S1, S2, available at www.jneurosci.org as supplemental material). 
The results from the mass spectrometry analysis suggested that, in addition to $\alpha 2 \mathrm{Na}, \mathrm{K}$-ATPase and GLAST, other glutamate transporters may be associated with additional ATPase subunits. To examine this further, immunoprecipitations were conducted on solubilized samples of rat forebrain and cerebellum. Western blot analysis of immunoprecipitations performed using $\alpha 2$ and $\alpha 3 \mathrm{Na}$,K-ATPase-specific antibodies showed that both antibodies selectively immunoprecipitated the respective target proteins (Fig. $4 A, B$ ). In the same samples, GLT-1 coimmunoprecipitated with both $\alpha 2$ and $\alpha 3 \mathrm{Na}, \mathrm{K}$-ATPase subunits in the forebrain samples (Fig. 4C), and GLAST was coimmunoprecipitated with $\alpha 2 \mathrm{Na}, \mathrm{K}$-ATPase in samples from the cerebellum (Fig. 4D).

The effects of glutamate transporter inhibitors and ouabain on glutamate transporter and $\mathrm{Na}, \mathrm{K}$-ATPase activities in synaptosomes

In light of our results showing copurification and coimmunoprecipitation of glutamate transporters and $\mathrm{Na}, \mathrm{K}$-ATPase in rat brain, we examined the effects of ouabain alone and in combination with glutamate transporter inhibitors on glutamate transporter activity in synaptosomes from rat forebrain and cerebellum. Western blot analysis showed high-level expression of GLT-1 and GLAST in forebrain and cerebellar synaptosomes (Fig. 5A), and all three $\alpha$ subunits of Na,K-ATPase were detected in both synaptosome preparations (Fig. $5 B$ ).

We used both $\left[{ }^{3} \mathrm{H}\right] \mathrm{D}$-aspartate and $\left[{ }^{3} \mathrm{H}\right] \mathrm{L}$-glutamate uptake to measure glutamate transporter activity in rat brain synaptosomes. Although $\alpha 2 \mathrm{Na}, \mathrm{K}$-ATPase is expressed primarily in glia with relatively little expression in neurons in the adult CNS (Peng et al., 1997; Moseley et al., 2007), we observed robust inhibition by ouabain of glutamate transporter activity in synaptosomal preparations from forebrain and cerebellum (Fig. 5C,D). However, the heterogeneous nature of synaptosomal preparations and the fact that they contain glial fragments is well documented (Henn et al., 1976; Kanerva et al., 1978; Nakamura et al., 1993). Moreover, the predominant transporter activity in similar forebrain preparations has been reported to be "EAAT2 like" (i.e., GLT-1) in its pharmacology (Dowd et al., 1996; Robinson and Dowd, 1997; Gegelashvili and Schousboe, 1998; Koch et al., 1999). In the glutamate transporter assays, sodium dependency was tested by excluding sodium ions from the uptake assay buffer; this resulted in greatly reduced transport activity in forebrain and cerebellum synaptosomes compared with control conditions conducted in the presence of sodium (Fig. 5C,D).

In the presence of sodium ions, the nonselective EAAT inhibitor TBOA inhibited D-aspartate uptake by $88.3 \pm 1.5 \%$ in forebrain synaptosomes and by $63.6 \pm 3.5 \%$ in cerebellar synaptosomes, whereas $1 \mathrm{~mm}$ ouabain inhibited $37.4 \pm 1.8$ and $34.2 \pm$ $2.0 \%$ of $\left[{ }^{3} \mathrm{H}\right] \mathrm{D}$-aspartate uptake in forebrain and cerebellar synaptosome preparations, respectively (Fig. $5 C, D$ ). Interestingly, in forebrain synaptosomes, the GLT-1-selective inhibitors DHK and WAY213613 inhibited D-aspartate uptake to a level similar to, albeit slightly lower, than that of ouabain $(30.0 \pm 1.3$ and $32 \pm$ $1.4 \%$, respectively) (Fig. $5 C$ ). In the cerebellar synaptosomes (Fig. $5 D$ ), these compounds produced a lower level of inhibition compared with forebrain synaptosomes, consistent with the lower level of expression of GLT-1 in cerebellum compared with forebrain. In both forebrain and cerebellar synaptosomes, when DHK or WAY213613 was added simultaneously with $1 \mathrm{mM}$ ouabain, a small, nonsignificant enhancement of the inhibition of D-aspartate uptake was observed compared with ouabain alone (Fig. 5C,D). The relatively small effects of DHK and WAY213613 in cerebellar synaptosomes when each was tested alone and the
A.

\section{IP: $\alpha_{2} \mathrm{Na}, \mathrm{K}-\mathrm{ATPase}$ SOL. FB CB $-A B$}

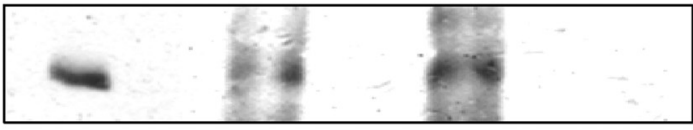

WB: $\alpha_{2}$ Na,K-ATPase

B.

\section{IP: $\alpha_{3} \mathrm{Na}, \mathrm{K}-\mathrm{ATPase}$}

SOL. FB -AB

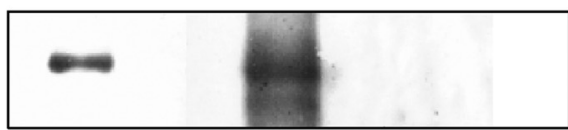

WB: non-selective $\alpha$ Na.K-ATPase

C.

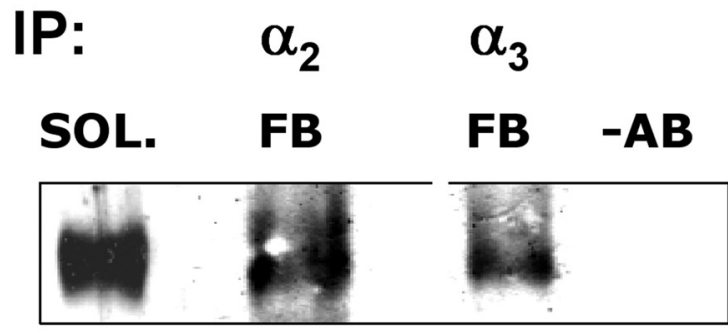

WB: GLT-1

D.

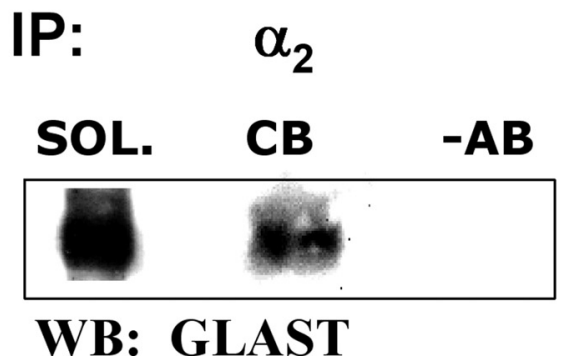

Figure 4. Coimmunoprecipitation of GLAST and GLT- 1 with $\alpha 2$ and $\alpha 3 \mathrm{Na}$, K-ATPase in rat brain. $\boldsymbol{A}, \boldsymbol{B}$, Western blots (WB) of $\alpha 2(\boldsymbol{A})$ and $\alpha 3 \mathrm{Na}$, K-ATPase ( $\boldsymbol{B}$ ) showing immunoprecipitation (IP) from rat forebrain (FB) and/or cerebellum (CB) using anti- $\alpha 2$ and $\alpha 3 \mathrm{Na}$, K-ATPase antibodies. C, Western blot showing coimmunoprecipitation of GLT-1 with $\alpha 2$ and $\alpha 3 \mathrm{Na}$, KATPase from rat forebrain. D, Coimmunoprecipitation of GLAST with $\alpha 2 \mathrm{Na}$, K-ATPase in rat cerebellum. SOL., Crude solubilized membranes from forebrain or cerebellum used as a positive control for the antibody on the Western blot; $-A B$, negative control excluding antibody from the immunoprecipitation. 
A. Expression of glutamate transporters

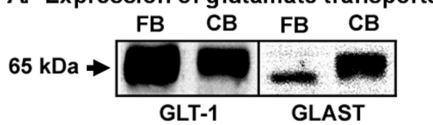

C. Forebrain synaptosomes

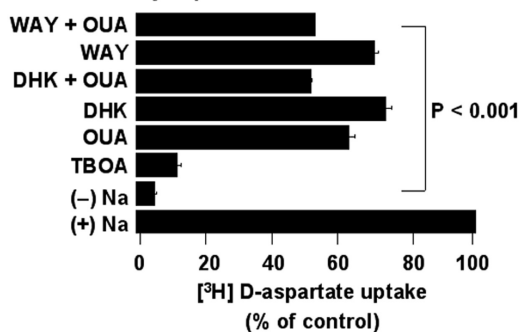

(\% of control)

D. Cerebellar synaptosomes

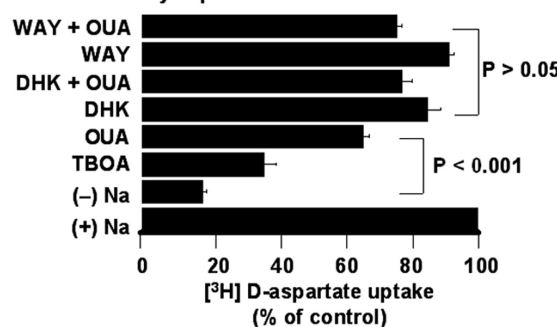

(\% of control)

E. Concentration-dependent inhibition by ouabain
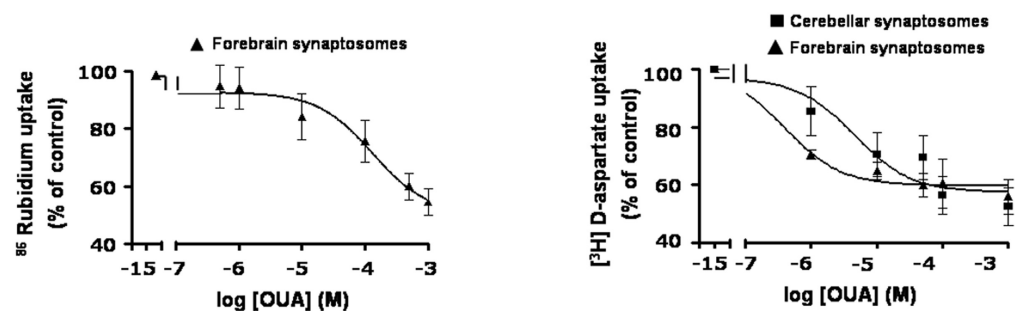

Figure 5. Inhibition of $\left[{ }^{3} \mathrm{H}\right] \mathrm{D}$-aspartate, $\left[{ }^{3} \mathrm{H}\right] \mathrm{L}$-glutamate, and rubidium- 86 uptake by ouabain in synaptosomes from rat forebrain and cerebellum. $\boldsymbol{A}$, Western blot analysis of forebrain (FB) and cerebellar (CB) synaptosomes demonstrating expression of GLAST and GLT-1. $\boldsymbol{B}$, Western blot analysis of forebrain (FB) and cerebellar (CB) synaptosomes demonstrating expression of $\alpha 1-\alpha 3$ isoforms of Na,K-ATPase. $\boldsymbol{C}, \boldsymbol{D}$, Results of D-aspartate and L-glutamate uptake assays in forebrain $(\boldsymbol{C})$ and cerebellar $(\boldsymbol{D})$ synaptosomes expressed as percentage of control [sodium-containing buffer, $(+) \mathrm{Na}$ ]. Inhibition of both D-aspartate and L-glutamate uptake was observed with the nonselective EAAT inhibitor TBOA (200 $\mu \mathrm{m})$, the GLT-1-selective inhibitors DHK (200 $\mu \mathrm{M})$ and WAY213613 (WAY; $1 \mu \mathrm{M}$ ), and ouabain (OUA; $1 \mathrm{~mm}$ ). Each column represents the mean and SEM of three to seven experiments. (-) $\mathrm{Na}$, Omission of sodium from the assay buffer. $\boldsymbol{E}$, Left, Concentration-dependent inhibition of rubidium-86 uptake by ouabain in rat forebrain $\left(\boldsymbol{\Delta} ; \mathrm{IC} 50\right.$ of $\left.1.36 \times 10^{-4} \mathrm{M}\right)$ synaptosomes. The results are expressed as percentage of control [sodium-containing buffer, $(+) \mathrm{Na}$ ]. Each point represents the mean \pm SEM of six experiments done in triplicate. $\boldsymbol{E}$, Right, Concentration-dependent inhibition of $\left[{ }^{3} \mathrm{H}\right] \mathrm{D}$-aspartate uptake by ouabain in rat forebrain $\left(\mathbf{A} ; \mathrm{IC} 50\right.$ of $\left.1.62 \times 10^{-5} \mathrm{M}\right)$ and cerebellar $\left(\square ; \mathrm{IC}\right.$ of $\left.2.61 \times 10^{-5} \mathrm{M}\right)$ synaptosomes. Results are expressed as percentage of control [sodium-containing buffer, $(+) \mathrm{Na}$ ]. Each point represents the average of two experiments done in triplicate. $p$ values compare test condition with controls without drug.

lack of an enhancement when given simultaneously with ouabain indicated that GLAST, which is insensitive to DHK and WAY213613 at the concentrations used, may be the predominant glutamate transporter associated with $\mathrm{Na}, \mathrm{K}$-ATPases in the cerebellum. Similar results with ouabain and transporter inhibitors were observed when $\left[{ }^{3} \mathrm{H}\right] \mathrm{L}$-glutamate was used instead of $\left[{ }^{3} \mathrm{H}\right] \mathrm{D}$ aspartate (Fig. 4C,D, right panels).

A dose-response analysis of ouabain on inhibition of $\left[{ }^{3} \mathrm{H}\right] \mathrm{D}-$ aspartate uptake was conducted on forebrain and cerebellar synaptosomes. In both preparations, ouabain inhibited $\left[{ }^{3} \mathrm{H}\right]_{\mathrm{D}}-$ aspartate uptake in a dose-dependent manner (Fig. 5E, right). Substantial inhibition was seen with $1 \mu \mathrm{M}$ ouabain, especially in forebrain synaptosomes. This low concentration of ouabain selectively inhibits the rat $\alpha 2$ and $\alpha 3$ ATPase subunits, which are highly sensitive to inhibition by this drug; at concentrations above $\sim 50 \mu \mathrm{M}$, all three ATPase $\alpha$ subunits $(\alpha 1-\alpha 3)$ are inhibited
(Hansen, 2003). The observation that additional inhibition of glutamate transporter activity was seen at higher concentration of ouabain $(100-1000 \mu \mathrm{M})$ compared with low $(1 \mu \mathrm{M})$ suggests that a subpopulation of glutamate transporters may also be coupled to $\alpha 1 \mathrm{Na}, \mathrm{K}$-ATPase, which, in the rat, is much less sensitive to ouabain (Shull et al., 1986; Crambert et al., 2004).

A dose-response analysis of ouabain on the ion pumping activity of $\mathrm{Na}, \mathrm{K}$-ATPase was performed using radioactive rubidium-86 as a tracer for potassium ions. In forebrain synaptosomes, the ion pumping activity was $\sim 100$-fold less sensitive to ouabain compared with glutamate transporter activity (Fig. $5 E$, left). These findings indicate that glutamate transporters are broadly sensitive to low and high concentrations of ouabain, whereas the ion pumping activity of $\mathrm{Na}, \mathrm{K}$-ATPase in synaptosomes is only inhibited by high ouabain concentrations. The latter observation is consistent with a previous report (Brodsky and Guidotti, 1990) demonstrating that $73 \%$ of Na,K-ATPase-mediated rubidium uptake in rat synaptosomes displays very low sensitivity to ouabain (mediated by $\alpha 1 \mathrm{Na}, \mathrm{K}$-ATPase), similar to that shown here in Figure $5 E$. Our observation that low ouabain concentrations inhibited glutamate transporters but not $\mathrm{Na}, \mathrm{K}$ ATPase ion pumping activity might be explained by a higher proportion of glutamate transporters being coupled to the high-affinity $\alpha 2$ and $\alpha 3$ Na,K-ATPases rather than the low-affinity $\alpha 1$ subunit and/or because the rubidium-86 assay measures total potassium flux of which only part of the flux is associated with $\mathrm{Na}, \mathrm{K}-\mathrm{ATPase}$. Alternatively, there may be a mechanistic dissociation of the two functions such that the ion pumping activity of $\mathrm{Na}, \mathrm{K}-\mathrm{ATP}$ ase is not required for the modulation of glutamate transporter function. For example, the differential ouabain sensitivity might be linked to the ouabain-induced, Src-mediated signaling mechanisms of $\mathrm{Na}, \mathrm{K}-\mathrm{ATP}$ ase (see Discussion).

The effects of glutamate transporter inhibitors and ouabain on glutamate transporter activity in cultured astrocytes Glutamate transporter expression and activity was also measured in cultured rat astrocytes prepared from the cerebral cortex of 2-d-old rats. Western blot analysis in which each sample was normalized for protein (10 $\mu \mathrm{g}$ protein per lane) showed that, at $10-14 \mathrm{~d}$ in vitro, astrocytes expressed GLAST but little (if any) GLT-1 (Fig. 6A). The expression of GLAST but not GLT-1 has also been reported in cultures of human fetal astrocytes (Gegelashvili et al., 2007). The $\alpha 2$ $\mathrm{Na}, \mathrm{K}$-ATPase subunit was expressed as was a very low level of $\alpha 1$ $\mathrm{Na}, \mathrm{K}-\mathrm{ATPase}$, no $\alpha 3 \mathrm{Na}, \mathrm{K}$-ATPase expression was observed (Fig. $6 B)$. In the $\left[{ }^{3} \mathrm{H}\right] \mathrm{D}$-aspartate uptake assay, neither of the GLT-1 selective inhibitors DHK or WAY213613 significantly affected 
D-aspartate uptake in the cultured astrocytes, and neither drug significantly affected the level of uptake inhibition when added together with ouabain compared with ouabain alone (Fig. 6C). Ouabain displayed a bimodal effect on glutamate transporter activity. Ouabain concentrations of $50 \mu \mathrm{M}$ and above inhibited uptake whereas, surprisingly, and in contrast to the findings in synaptosomes, $10 \mu \mathrm{M}$ had no effect, whereas $1 \mu \mathrm{M}$ produced a significant stimulation of D-aspartate uptake (39\% above control) (Fig. 6C). These results indicate that cultured rat astrocytes expressing GLAST but not GLT-1 respond differently to ouabain compared with synaptosomes expressing both GLT-1 and GLAST; whereas higher concentrations of ouabain inhibited glutamate transport in both preparations, low concentrations inhibited transport in synaptosomes but stimulated uptake in cultured astrocytes. The observation that low ouabain concentrations inhibited uptake in cerebellar synaptosomes but stimulated uptake in cultured astrocytes might be related to differences in expression of $\alpha 1$ and $\alpha 3 \mathrm{Na}, \mathrm{K}$-ATPase, which were present in the both the forebrain and cerebellar synaptosomes but absent from the cultured astrocytes.

Expression and coimmunoprecipitation studies in HEK-293T cells

To determine whether the results obtained in brain synaptosomal preparations and cultured astrocytes could be recapitulated in a simplified cell system, coimmunoprecipitation experiments were conducted in transfected HEK-293T cells. Western blot analysis conducted on mock-transfected HEK-293T cells to characterize the basal endogenous level of expression of GLAST, GLT-1, and ATPase $\alpha$ subunits showed a low level of GLAST but little if any GLT-1; these cells also expressed $\alpha 1$ and $\alpha 3 \mathrm{Na}$,K-ATPase, but the $\alpha 2 \mathrm{Na}$,K-ATPase subunit was not detected (Fig. 7A, mock-transfected lanes). Coimmunoprecipitation experiments were conducted on HEK-293T cells cotransfected with GLAST, $\alpha 2$, and $\beta 2 \mathrm{Na}$,K-ATPase subunits. The GLAST antibody immunoprecipitated GLAST and also coimmunoprecipitated $\alpha 2 \mathrm{Na}, \mathrm{K}-\mathrm{ATPase}$, and, conversely, an $\alpha 2 \mathrm{Na}, \mathrm{K}-\mathrm{ATPase}$-selective antibody immunoprecipitated $\alpha 2$ $\mathrm{Na}, \mathrm{K}-\mathrm{ATP}$ ase and coimmunoprecipitated GLAST (Fig. 7B). These results demonstrate that, as observed in rat brain tissue, GLAST and $\alpha 2 \mathrm{Na}, \mathrm{K}-\mathrm{ATPase}$ are associated with each other in the same molecular complexes in transiently transfected HEK-293T cells.

The effects of protein kinase inhibitors on $\left[{ }^{3} \mathrm{H}\right] \mathrm{D}$-aspartate uptake in synaptosomes

One potential mechanism accounting for the ouabain-mediated inhibition of glutamate transporters could be through the actions of protein kinases. Na,K-ATPase is known to be part of a complex

C.

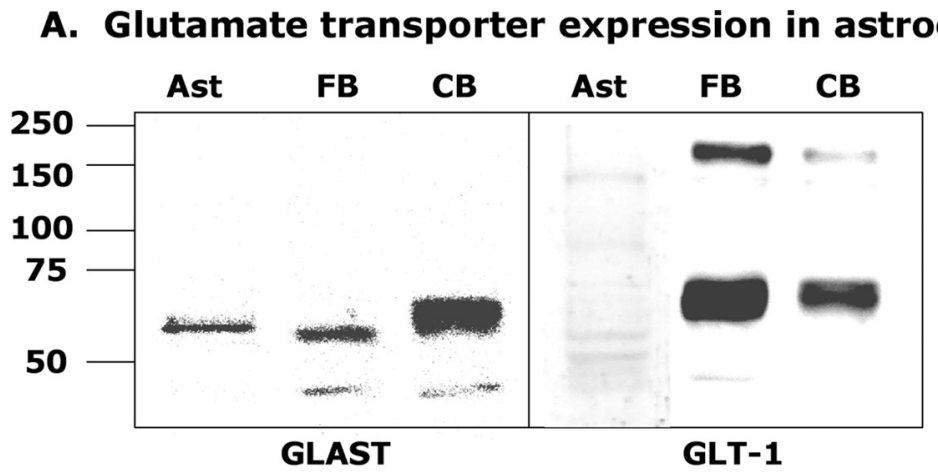

B. Na,K-ATPase expression in astrocytes
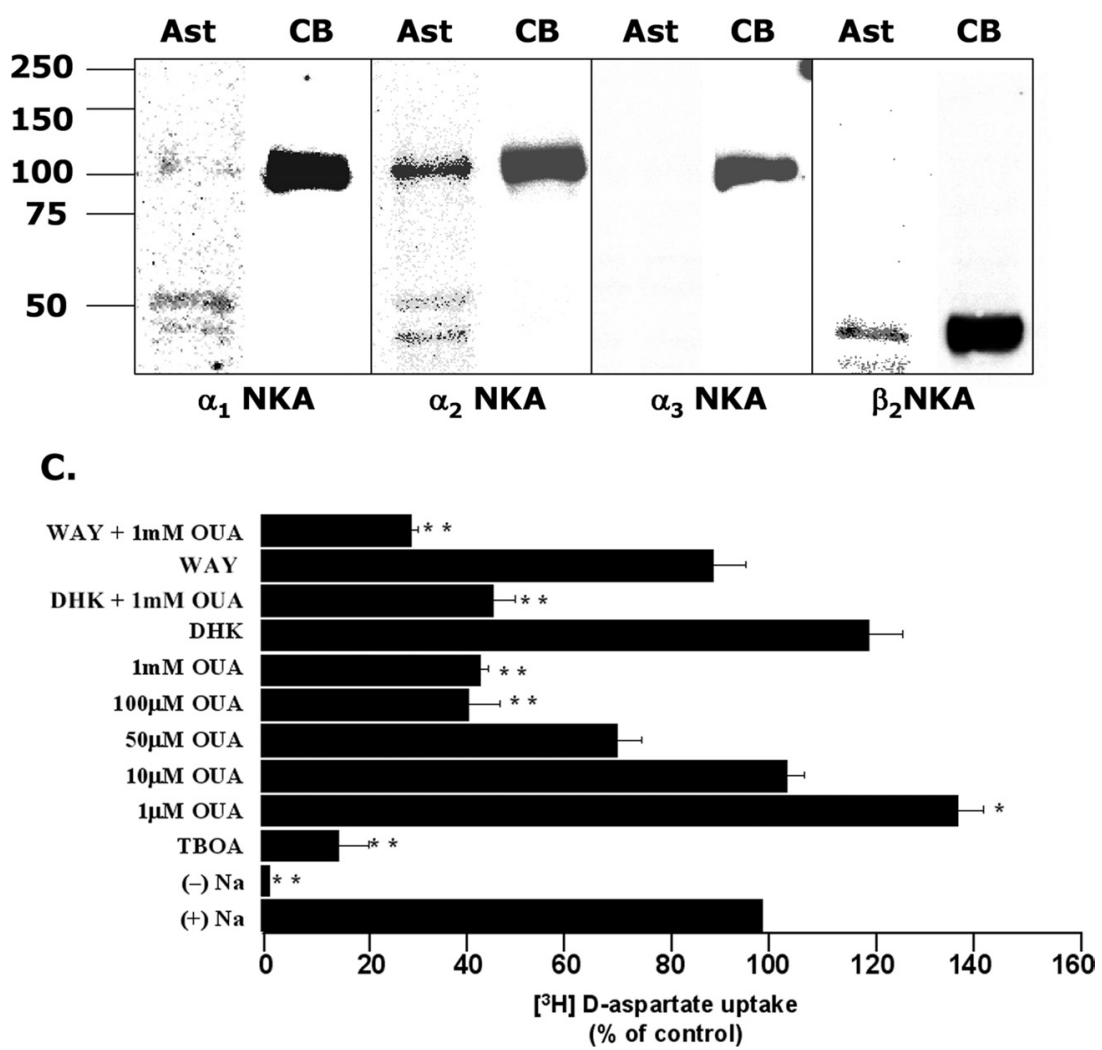

Figure 6. Expression of glutamate transporters and Na,K-ATPase subtypes and drug effects on D-aspartate uptake in rat astrocytes. $\boldsymbol{A}$, Western blot analysis of cultured astrocytes (Ast; 11-14 $\mathrm{d}$ in vitro) showed expression of GLAST (65 kDa) but not GLT-1. $B$, Western blots of astrocytes demonstrating expression of $\alpha 1, \alpha 2$, and $\beta 2$ subunits of Na, K-ATPase (NKA; 100, 100, and $45 \mathrm{kDa}$, respectively) but not the $\alpha 3$ subunit. Forebrain (FB) and cerebellar (CB) membranes were used as positive controls. $C$ Summary of drug effects on $\left[{ }^{3} \mathrm{H}\right] \mathrm{D}$-aspartate uptake in cultured astrocytes expressed as percentage of control [sodium-containing buffer only, (+) Na]. Each bar represents the mean \pm SEM of three to five experiments. DHK (200 $\mu \mathrm{M})$ and WAY213613 (1 $\mu \mathrm{M})$ did not significantly inhibit uptake, whereas TBOA (200 $\mu \mathrm{M})$ and ouabain (OUA) at $>50 \mu \mathrm{m}$ significantly inhibited uptake. Ouabain at $1 \mu$ m significantly stimulated D-aspartate uptake. ${ }^{*} p<0.05,{ }^{* *} p<0.001$ compared with control $(+\mathrm{Na})$.

that includes Src and other proteins associated with cellular signaling, and inhibition of the ATPase by ouabain stimulates Src activity (Tian et al., 2006). To investigate the possible role of Src and other kinases in ouabain modulation of glutamate transporters, two potent Src inhibitors, PP2 and SU6656, were tested on $\left[{ }^{3} \mathrm{H}\right] \mathrm{D}$-aspartate uptake into forebrain synaptosomes. PP2 inhibits Src with an $\mathrm{IC}_{50}$ of $1-5 \mu \mathrm{M}$ and has a $>100$-fold selectivity for Src family kinases over other tyrosine kinases, whereas SU6656 is an exceptionally potent inhibitor of Src with an $\mathrm{IC}_{50}$ of $280 \mathrm{nM}$ (Hanke et al., 1996). We used concentrations of PP2 (100 nM) and SU6656 $(1 \mu \mathrm{M})$ that were low enough to retain specificity for 


\section{A. Na,K-ATPase and glutamate transporter expression} in HEK-293T cells

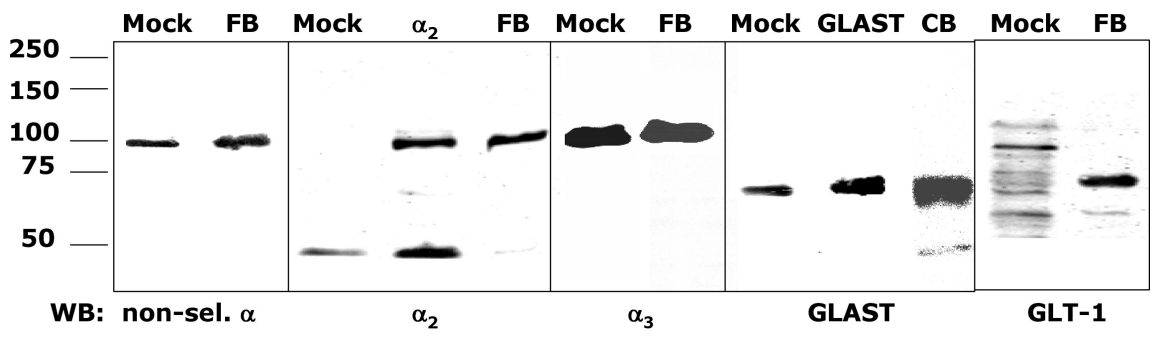

\section{B. Co-immunoprecipitation of GLAST and $\alpha_{2} \mathrm{Na}, \mathrm{K}$-ATPase from $\alpha_{2} \beta_{2}$ GLAST HEK-293T cells}

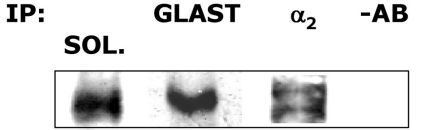

WB: GLAST

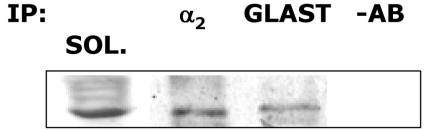

WB: $\alpha_{2}$ Na,K-ATPase

Figure 7. Expression of glutamate transporters and Na,K-ATPase and coimmunoprecipitation of GLAST and $\alpha 2 \mathrm{Na}, \mathrm{K}$-ATPase from $\alpha 2 \beta 2$ GLAST-transfected HEK-293T cells. A, Western blot (WB) analysis of mock-transfected HEK-293T cells (Mock) showing expression of $\alpha 1$ and $\alpha 3 \mathrm{Na}$,K-ATPase (100 kDa) and GLAST (monomer at $65 \mathrm{kDa}$ ) and the absence of $\alpha 2 \mathrm{Na}$, K-ATPase and little or no GLT-1. Rat forebrain (FB) membranes were used as positive controls. $\boldsymbol{B}$, Antibodies selective for $\alpha 2 \mathrm{Na}$, K-ATPase and GLAST were used to immunoprecipitate the respective proteins from HEK-293T cells cotransfected with GLAST, $\alpha 2$, and $\beta 2$ Na, K-ATPase CDNAs. The samples were analyzed by Western blots probed with GLAST (left) and $\alpha 2 \mathrm{Na}$, K-ATPase-specific (right) antibodies. The $\alpha 2$ subunit of Na,K-ATPase (seen at $100 \mathrm{kDa}$ ) coimmunoprecipitated using the GLAST antibody, and, conversely, GLAST (dimer seen at $130 \mathrm{kDa}$ ) coimmunoprecipitated using the $\alpha 2 \mathrm{Na}$,K-ATPase-specific antibody. SOL., Crude solubilized HEK-293T cells cotransfected with GLAST, $\alpha 2$, and $\beta 2 \mathrm{Na}$, K-ATPase; $-\mathrm{AB}$, negative control excluding antibody in the immunoprecipitation step.

Src family protein kinases. Both compounds significantly inhibited uptake compared with controls; the level of inhibition was similar to, and not significantly different from, that of ouabain (Fig. 8A). The effects of PP2 or SU6656 when combined with ouabain were not significantly different from that of ouabain alone. In contrast to Src inhibitors, inhibitors of PKA (H89), PKC (staurosporine), and phosphatidylinositol 3-kinase (PI3K) (wortmannin) did not significantly inhibit $\mathrm{D}$-aspartate uptake (Fig. 8 B). These results demonstrate that, in synaptosomes, inhibition of Src, but not PKA, PKC, or PI3K, inhibits glutamate transporter activity to a level that is similar to that of ouabain.

\section{Discussion}

The putative mechanism for driving glutamate transporter activity against a large concentration gradient is based on the indirect coupling of glutamate uptake to $\mathrm{Na}, \mathrm{K}$-ATPase activity. $\mathrm{Na}, \mathrm{K}$ ATPase generates an inwardly directed electrochemical sodium gradient that is used by the transporters to drive the uphill transport of the neurotransmitters. The stoichiometry of ion transfer during glutamate transporter activity has been determined to be $3 \mathrm{Na}^{+}: 1 \mathrm{H}^{+}: 1 \mathrm{~K}^{+}$:glutamate (Kanner, 2006). Under physiological conditions, the inwardly directed sodium gradient and outwardly directed potassium gradient promote the accumulation of the transmitter in the cell against its concentration gradient; conversely, at elevated external potassium concentrations, the transporters mediate transmitter efflux out of cells. Previous work has shown a tight coupling of glutamate transporters with $\mathrm{Na}, \mathrm{K}$ ATPase activity whereby, during prolonged, elevated extracellular glutamate levels, intracellular sodium is also elevated to a new steady state in which sodium influx via the transporter is precisely matched by extrusion through the pump (Chatton et al., 2000).
Because glutamate transporters and $\mathrm{Na}, \mathrm{K}-$ ATPases both have an absolute requirement for sodium and potassium, the coupled transporter/ATPase protein complexes may be mutually dependent on each other for satisfying their ion requirements. Our findings that glutamate transporters and $\mathrm{Na}, \mathrm{K}-\mathrm{ATPases}$ are physically associated in the same protein complexes indicates a direct rather than indirect relationship between glutamate transporters and Na,K-ATPases.

The present study was prompted in part by the anatomical overlap of glutamate transporters and subunits of $\mathrm{Na}, \mathrm{K}$ ATPase in the CNS. For example, previous work has shown overlapping patterns of immunostaining of $\alpha 2 \mathrm{Na}, \mathrm{K}$-ATPase with GLT- 1 and GLAST in the rat cerebral cortex in which $\alpha 2$-containing astrocytic processes are primarily associated with axo/ dendritic appositions and asymmetrical (glutamatergic) synaptic junctions but not with symmetric GABAergic junctions (Cholet et al., 2002). Our immunocytochemical results from the rat cerebellar cortex demonstrate that $\alpha 2 \mathrm{Na}, \mathrm{K}$-ATPase and GLAST are both highly expressed in the processes of the Bergmann glia infiltrating the molecular layer of the cerebellar cortex. At parallel and climbing-fiber synapses on Purkinje neurons, astrocytic Bergmann glial cells envelop individual excitatory contacts and act as physical barriers between neighboring synapses; this arrangement presumably brings glutamate transporters closer to synaptic release sites. Thus, the contribution of glutamate transporters to cerebellar synaptic transmission is probably substantial and, by comparison, more robust than that which is seen in the hippocampus (Tzingounis and Wadiche, 2007).

In the rat hippocampus in which GLT-1 is highly expressed, the GLT-1b splice variant showed some astrocytic coexpression with $\alpha 2 \mathrm{Na}, \mathrm{K}$-ATPase. More extensive coexpression was observed with the GLT-1a isoform and $\alpha 3 \mathrm{Na}, \mathrm{K}-\mathrm{ATP}$ ase. $\alpha 3 \mathrm{Na}, \mathrm{K}$ ATPase is thought to be selectively expressed in neurons of the adult brain (Moseley et al., 2007). Therefore, our observation that GLT-1a is expressed in some of the same cells as the $\alpha 3$ subunit provides additional evidence that, in addition to the well established expression in astrocytes, GLT-1a is also expressed in some neurons. Indeed, at least four splice variants of GLT-1 are expressed in rodent brain (Peacey et al., 2009), and a growing number of reports have demonstrated neuronal expression of GLT-1 (Chen et al., 2004; Bassan et al., 2008; González-González et al., 2008).

We were surprised that, although high ouabain concentrations inhibited glutamate transport in cultured astrocytes, low concentrations stimulated D-aspartate uptake; a stimulatory effect was never observed in forebrain or cerebellar synaptosomes at any concentration of ouabain. The cultured astrocytes expressed GLAST but not GLT-1, whereas forebrain and cerebellar synaptosomes expressed both glutamate transporters. The stimulatory effect of low ouabain seen in cultured astrocytes, presumably mediated by GLAST, might have been masked by the inhib- 
A.
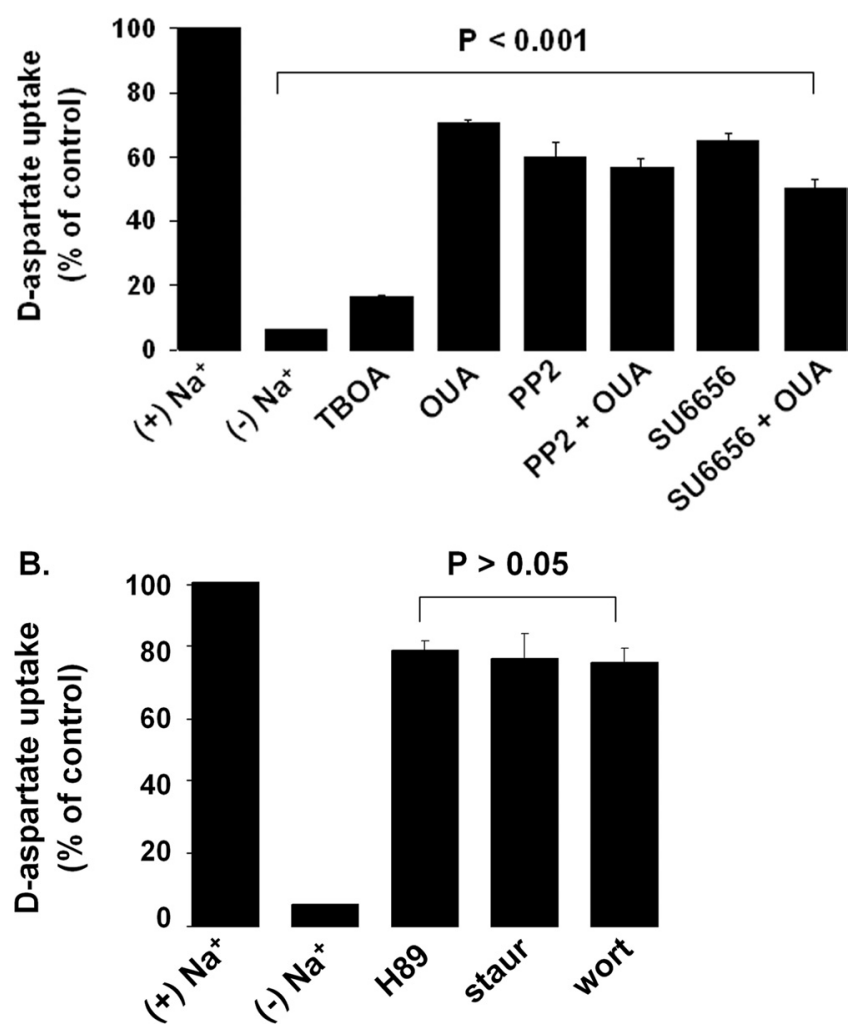

Figure 8. Effects of protein kinase inhibitors on $\left[{ }^{3} \mathrm{H}\right] \mathrm{D}$-aspartate uptake in rat forebrain synaptosomes. $\boldsymbol{A}$, The effects of Src kinase inhibitors on [ $\left.{ }^{3} \mathrm{H}\right] \mathrm{D}$-aspartate uptake in synaptosomes. The results are expressed as percentage of control [sodium-containing buffer only, $(+)$ $\mathrm{Na}$ ]. D-Aspartate uptake was significantly inhibited in the presence of the Src inhibitors PP2 (100 nM) and SU6656 $(1 \mu \mathrm{M})$. OUA, Ouabain. $\boldsymbol{B}$, The effects of other protein kinase inhibitors on D-aspartate uptake in synaptosomes. In contrast to Src inhibitors, no significant effects were observed with the PKA inhibitor H89 (10 $\mu \mathrm{M}$ ), the PI3K inhibitor wortmannin (Wort; $1 \mu \mathrm{m}$ ), or the PKC inhibitor staurosporine (Staur; $10 \mu \mathrm{m}$ ). Each condition shown in $\boldsymbol{A}$ and $\boldsymbol{B}$ represents the mean \pm SEM of three experiments. Ouabain was used at $1 \mathrm{~mm}$ and TBOA at $200 \mu \mathrm{M}$.

itory effects on GLT-1 in the synaptosomes. Interestingly, wholecell patch-clamp analysis conducted on isolated guinea pig, canine, and human cardiac myocytes to directly measure the sodium pump current showed that nanomolar concentrations of ouabain and dihydro-ouabain stimulated Na,K-ATPase activity (Gao et al., 2002). When the contributions of the high ouabain affinity $\alpha 2$ (in pig cardiomyocytes) and $\alpha 3$ (in canine cardiomyocytes) isoforms could be separated from that of the low-affinity $\alpha 1$ isoform, it was only the high-affinity isoforms that were stimulated. These observations prompted Gao et al. (2002) to suggest that this may represent a novel mechanism of isoform-specific regulation of $\mathrm{Na}$,K-ATPase in the heart by nanomolar concentrations of endogenous ouabain-like molecules. Considerable evidence exists for the presence of endogenous ouabain-like molecules or "endobains" in tissues that may serve to regulate $\mathrm{Na}, \mathrm{K}$ ATPase activity (Hamlyn et al., 1991; Goto et al., 1992; Schoner and Scheiner-Bobis, 2007). Endogenous ouabain molecules may participate in modulating glutamate transporter activity via the high ouabain affinity $\alpha 2 \mathrm{Na}, \mathrm{K}$-ATPase expressed in astrocytes and possibly by the high-affinity $\alpha 3$ subunit present in neurons.

Although the focus of our work has been on the regulation of glutamate transporters by $\mathrm{Na}, \mathrm{K}$-ATPases, there is also evidence that glutamate transporters can modulate $\mathrm{Na}$,K-ATPases. Gegelashvili et al. (2007) have shown that, in human fetal astrocytes, application of glutamate stimulates increased expression of
GLAST and increased activity of Na,K-ATPase. The increased $\mathrm{Na}, \mathrm{K}$-ATPase activity was attributable to increased targeting of the $\gamma$ subunit (FXYD2) to the plasma membrane. The FXYD2 protein $(\gamma)$ subunit is an auxiliary component of some but not all $\mathrm{Na}, \mathrm{K}-\mathrm{ATP}$ ase holomeric complexes that appears to modulate the affinity for sodium and potassium. It was concluded that increased activity of GLAST directs FXYD2/ $\gamma$ to the cell surface and that this in turn leads to the activation of the astroglial sodium pump, presumably attributable to the modulatory effect of the $\gamma$ subunit on the kinetic parameters of the catalytic $\alpha$ subunit of the Na,K-ATPase. Gegelashvili et al. (2007) also suggested that the cytoplasmic domain of the $\gamma$ subunit, which is enriched with basic amino acid residues, might act as an interface for binding directly to the negatively charged amino acids in the extreme $\mathrm{C}$ terminus of GLAST.

The involvement of protein kinases in the regulation of glutamate transporters by Na,K-ATPase was also explored. The effects of protein kinases on glutamate transporters are complex and vary considerably depending on the preparation and conditions. Protein kinase $\mathrm{C}$ has been shown to downregulate GLT-1 in C6 glioma cells (Susarla and Robinson, 2008), whereas other studies have shown that GLT-1 and GLAST are upregulated by growth factor-induced tyrosine kinase activation and that this effect can be blocked by the tyrosine kinase inhibitors (Zelenaia et al., 2000; Koeberle and Bähr, 2008). Ouabain has been shown to induce intracellular calcium oscillations via a direct interaction between the N-terminal tail of Na,K-ATPase and the inositol 1,4,5trisphosphate-ligand binding domain of the $\mathrm{IP}_{3}$ receptor (Mikoshiba, 2007), and low concentrations of ouabain can trigger slow, low-frequency calcium oscillations that activate the transcription factor nuclear factor $\kappa \mathrm{B}$. It is possible that PKC or other calciumsensitive kinases may be stimulated by ouabain acting on $\mathrm{Na}, \mathrm{K}$ ATPase, which then affects glutamate transporter function.

Pertinent to the issue of linking Na,K-ATPases to glutamate transporters is the consistent finding that ouabain elicits activation of Src tyrosine kinases (Xie, 2003), which subsequently induces recruitment and phosphorylation of the extracellular signal-regulated kinase ERK (Pierre et al., 2008). We demonstrate here for the first time that inhibitors of Src reduce glutamate transporter activity. Moreover, the level of glutamate transporter inhibition in synaptosomes was similar to that produced by ouabain, and inhibition after coapplication of Src inhibitors together with ouabain was not different from ouabain alone. Interestingly, Na,K-ATPase is known to form a complex with Src, and this signaling complex or "signalosome" operates independently of the ion transporting functions of the Na,K-ATPase (Xie, 2003; Liang et al., 2007). In addition, ouabain activation of Src occurs over a broad concentration range (Liang et al., 2007; Pierre et al., 2008) similar to what we observed with glutamate transporter function in synaptosomes. Based on these observations, we speculate that the inhibitory effect of ouabain on glutamate transporters could involve the participation of Src in an Na,K-ATPase/Src/ glutamate transporter protein complex. The finding that Src inhibitors produce the same inhibitory effect as ouabain on glutamate uptake suggests that the effect occurs independently of the phosphorylation function of Src and that Src, possibly via its Src homology $2 / 3$ domains, may be acting more as an adaptor protein (Boggon and Eck, 2004; Pawson, 2004), linking ouabaininduced conformational changes in $\mathrm{Na}, \mathrm{K}$-ATPase to modulation of glutamate transporter activity. Additional studies are required to address this idea.

Collectively, our data demonstrate that the glutamate transporters and $\mathrm{Na}, \mathrm{K}$-ATPases are present in the same macromolec- 
A.

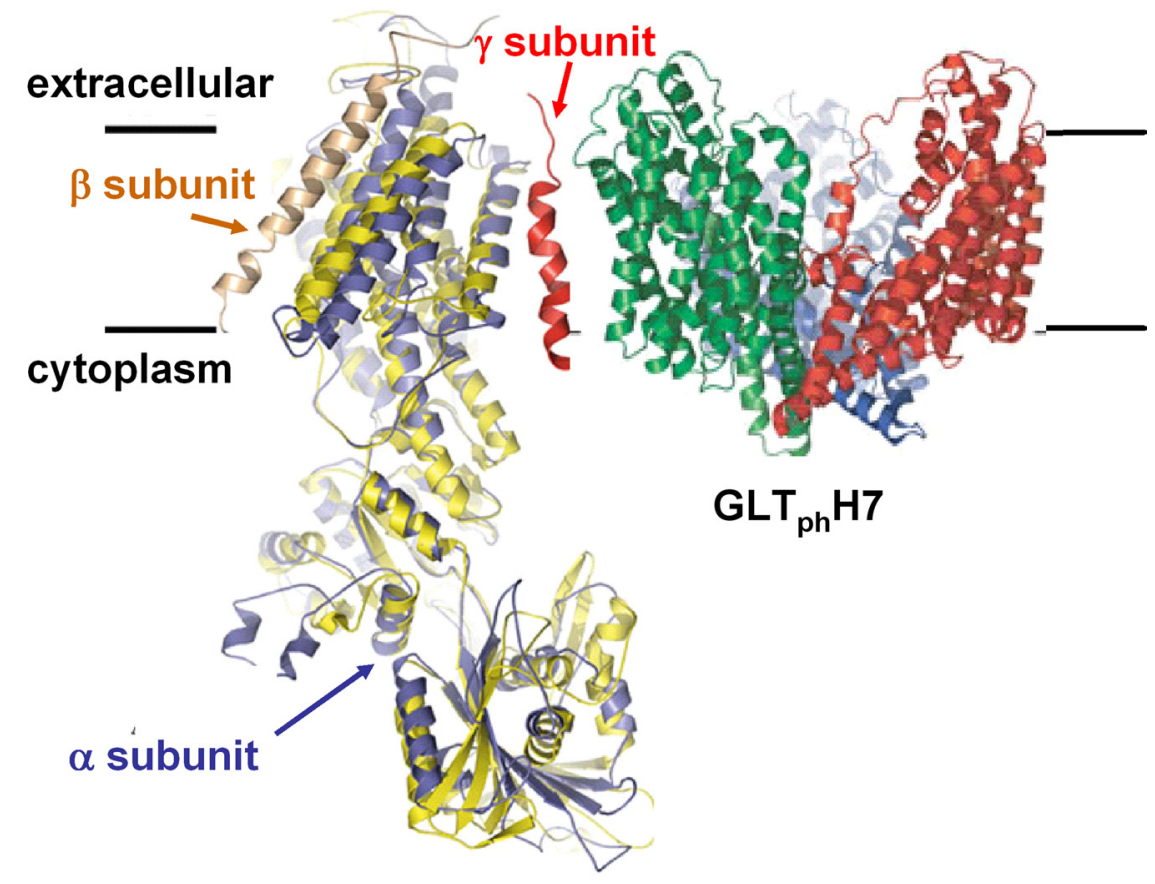

B.

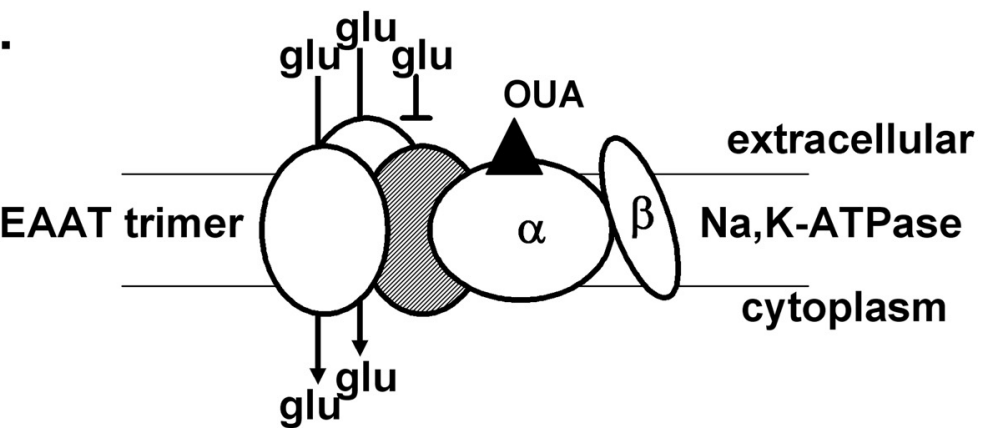

Figure 9. Structural and functional aspects of glutamate transporter and Na,K-ATPase interactions. A, Depictions of the crystal structures of the pig Na,K-ATPase and a glutamate transporter from Pyrococcus horikoshii (graphics taken from Morth et al., 2007 and Yernool et al., 2004, respectively). B, Hypothetical model of the juxtaposition of glutamate (Glu) transporters with $\mathrm{Na}, \mathrm{K}$ ATPase in which only one of the subunits within the trimeric structure of the transporter is associated with Na,K-ATPase.

ATPase/Src signalosome complex in which Src plays a regulatory role in glutamate transporter function.

In the course of these studies, we made the curious observation that, in a variety of cell types including rat forebrain and cerebellar synaptosomes (Fig. 5), cultured astrocytes (Fig. 6), and in the human embryonic kidney HEK-293T and Chinese hamster ovary cell lines (data not shown), typically approximately one-third to a maximum of approximately one-half of sodium-dependent glutamate uptake is susceptible to inhibition by ouabain, whereas the remaining one-half to twothirds is impervious to inhibition by ouabain. The consistency of this ratio across species and cell types suggests that some fundamental aspect of protein structure and function may be at play. A widely held view based on the crystal structure of the bacterial glutamate transporter, protein cross-linking experiments on mammalian transporters, fluorescence resonance energy transfer experiments, and other studies is that glutamate transporters are homo-trimers (Gendreau et al., 2004; Yernool et al., 2004). Intriguingly, additional evidence indicates that the individual protomers within a trimer appear to function independently of one another (Grewer et al., 2005; Koch et al., 2007).

Based on these findings, together with the results presented here, we propose an arrangement whereby one protomer within the trimer is associated with a molecule of $\mathrm{Na}, \mathrm{K}-\mathrm{ATP} a \mathrm{se}$ and is therefore inhibitable by ouabain, whereas the other two protomers are not in direct association with the $\mathrm{Na}, \mathrm{K}$-ATPase and therefore are not affected by, or are much less susceptible to, ouabain inhibition (Fig. 9B).

ular complexes and that transporter activity is regulated by the sodium/potassium pump. Our findings prompt an obvious question: how does this multiprotein complex operate from a mechanistic standpoint? Although this question cannot currently be answered, we can speculate based on the functional and structural information presently available, including the crystal structures of the pig Na,K-ATPase (Morth et al., 2007) and a bacterial glutamate transporter with 37\% homology to mammalian GLT-1 (Yernool et al., 2004) (Fig. 9A). Both proteins are thought to undergo conformational changes during activation, and both possess binding sites for sodium and potassium ions (Sweadner and Donnet, 2001; Kanner, 2006). A direct interaction between the proteins could promote mutually and optimally coordinated conformational shifts such that movement of the transmembrane segments of the sodium/potassium pump may facilitate glutamate transporter activity. We also note that a direct proteinprotein interaction and the participation of other signaling proteins, such as Src, are not mutually exclusive. In astrocytes (and possibly in neurons in which other combinations of neuronally expressed glutamate transporters and $\mathrm{Na}, \mathrm{K}$-ATPase subunits are present), glutamate transporters may exist as part of the $\mathrm{Na}, \mathrm{K}$ -
Such an arrangement would not only account for the consistently observed $\sim$ 1:2 ratio of ouabain-inhibited/ouabain-resistant glutamate transport but would also imply that a portion of glutamate uptake in the brain is acutely regulated by the status of ATPases, whereas the remaining larger portion may operate in a mode that is independent of the acute status of the Na,K-ATPase. The portion of glutamate transporter activity under direct control of ATPase via the protein-protein interaction may play a role as a fast synaptic activity or energy sensor, whereas activity of the ouabain-resistant fraction may depend indirectly on ATPase function by relying on ion gradients. Although this model is currently hypothetical, future studies will attempt to test these ideas.

\section{References}

Amara SG, Fontana AC (2002) Excitatory amino acid transporters: keeping up with glutamate. Neurochem Int 41:313-318.

Astrup J, Sørensen PM, Sørensen HR (1981) Oxygen and glucose consumption related to $\mathrm{Na}^{+}-\mathrm{K}^{+}$transport in canine brain. Stroke 12:726-730.

Bassan M, Liu H, Madsen KL, Armsen W, Zhou J, Desilva T, Chen W, Paradise A, Brasch MA, Staudinger J, Gether U, Irwin N, Rosenberg PA (2008) Interaction between the glutamate transporter GLT1b and the synaptic PDZ domain protein PICK1. Eur J Neurosci 27:66-82. 
Boggon TJ, Eck MJ (2004) Structure and regulation of Src family kinases. Oncogene 23:7918-7927.

Brodsky JL, Guidotti G (1990) Sodium affinity of brain $\mathrm{Na}(+)-\mathrm{K}(+)$ ATPase is dependent on isozyme and environment of the pump. Am J Physiol 258:C803-C811.

Canfield VA, Levenson R (1998) Domain swapping between Na,K- and $\mathrm{H}, \mathrm{K}-\mathrm{ATP}$ ase identifies regions that specify Na,K-ATPase activity. Biochemistry 37:7509-7516.

Chatton JY, Marquet P, Magistretti PJ (2000) A quantitative analysis of L-glutamate-regulated $\mathrm{Na}^{+}$dynamics in mouse cortical astrocytes: implications for cellular bioenergetics. Eur J Neurosci 12:3843-3853.

Chaudhry FA, Lehre KP, van Lookeren Campagne M, Ottersen OP, Danbolt NC, Storm-Mathisen J (1995) Glutamate transporters in glial plasma membranes: highly differentiated localizations revealed by quantitative ultrastructural immunocytochemistry. Neuron 15:711-720.

Chen W, Mahadomrongkul V, Berger UV, Bassan M, DeSilva T, Tanaka K, Irwin N, Aoki C, Rosenberg PA (2004) The glutamate transporter GLT1 is expressed in excitatory axon terminals of mature hippocampal neurons. J Neurosci 24:1136-1148.

Cholet N, Pellerin L, Magistretti PJ, Hamel E (2002) Similar perisynaptic glial localization for the $\mathrm{Na}+, \mathrm{K}+$-ATPase alpha 2 subunit and the glutamate transporters GLAST and GLT-1 in the rat somatosensory cortex. Cereb Cortex 12:515-525.

Crambert G, Schaer D, Roy S, Geering K (2004) New molecular determinants controlling the accessibility of ouabain to its binding site in human $\mathrm{Na}, \mathrm{K}-\mathrm{ATP}$ ase alpha isoforms. Mol Pharmacol 65:335-341.

de Carvalho Aguiar P, Sweadner KJ, Penniston JT, Zaremba J, Liu L, Caton M, Linazasoro G, Borg M, Tijssen MA, Bressman SB, Dobyns WB, Brashear A, Ozelius LJ (2004) Mutations in the $\mathrm{Na}^{+} / \mathrm{K}^{+}$-ATPase alpha3 gene ATP1A3 are associated with rapid-onset dystonia parkinsonism. Neuron 43:169-175.

De Fusco M, Marconi R, Silvestri L, Atorino L, Rampoldi L, Morgante L, Ballabio A, Aridon P, Casari G (2003) Haploinsufficiency of ATP1A2 encoding the $\mathrm{Na}^{+} / \mathrm{K}^{+}$pump alpha2 subunit associated with familial hemiplegic migraine type 2. Nat Genet 33:192-196.

Dowd LA, Coyle AJ, Rothstein JD, Pritchett DB, Robinson MB (1996) Comparison of $\mathrm{Na}^{+}$-dependent glutamate transport activity in synaptosomes, C6 glioma, and Xenopus oocytes expressing excitatory amino acid carrier 1 (EAAC1). Mol Pharmacol 49:465-473.

Fraser CL, Arieff AI (2001) Na-K-ATPase activity decreases with aging in female rat brain synaptosomes. Am J Physiol Renal Physiol 281:F674-F678.

Fremeau RT Jr, Troyer MD, Pahner I, Nygaard GO, Tran CH, Reimer RJ, Bellocchio EE, Fortin D, Storm-Mathisen J, Edwards RH (2001) The expression of vesicular glutamate transporters defines two classes of excitatory synapse. Neuron 31:247-260.

Gao J, Wymore RS, Wang Y, Gaudette GR, Krukenkamp IB, Cohen IS, Mathias RT (2002) Isoform-specific stimulation of cardiac $\mathrm{Na} / \mathrm{K}$ pumps by nanomolar concentrations of glycosides. J Gen Physiol 119:297-312.

Gegelashvili G, Schousboe A (1998) Cellular distribution and kinetic properties of high-affinity glutamate transporters. Brain Res Bull 45:233-238.

Gegelashvili M, Rodriguez-Kern A, Sung L, Shimamoto K, Gegelashvili G (2007) Glutamate transporter GLAST/EAAT1 directs cell surface expression of FXYD2/gamma subunit of Na, K-ATPase in human fetal astrocytes. Neurochem Int 50:916-920.

Gendreau S, Voswinkel S, Torres-Salazar D, Lang N, Heidtmann H, DetroDassen S, Schmalzing G, Hidalgo P, Fahlke C (2004) A trimeric quaternary structure is conserved in bacterial and human glutamate transporters. J Biol Chem 279:39505-39512.

González-González IM, García-Tardón N, Cubelos B, Giménez C, Zafra F (2008) The glutamate transporter GLT1b interacts with the scaffold protein PSD-95. J Neurochem 105:1834-1848.

Goto A, Yamada K, Yagi N, Yoshioka M, Sugimoto T (1992) Physiology and pharmacology of endogenous digitalis-like factors. Pharmacol Rev 44:377-399.

Grewer C, Balani P, Weidenfeller C, Bartusel T, Tao Z, Rauen T (2005) Individual subunits of the glutamate transporter EAAC1 homotrimer function independently of each other. Biochemistry 44:11913-11923.

Hamlyn JM, Blaustein MP, Bova S, DuCharme DW, Harris DW, Mandel F, Mathews WR, Ludens JH (1991) Identification and characterization of a ouabain-like compound from human plasma. Proc Natl Acad Sci U S A $88: 6259-6263$.
Hanke JH, Gardner JP, Dow RL, Changelian PS, Brissette WH, Weringer EJ, Pollok BA, Connelly PA (1996) Discovery of a novel, potent, and Src family-selective tyrosine kinase inhibitor. Study of Lck- and FynTdependent T cell activation. J Biol Chem 271:695-701.

Hansen O (2003) No evidence for a role in signal-transduction of $\mathrm{Na}^{+} / \mathrm{K}^{+}$ATPase interaction with putative endogenous ouabain. Eur J Biochem 270:1916-1919.

Henn FA, Anderson DJ, Rustad DG (1976) Glial contamination of synaptosomal fractions. Brain Res 101:341-344.

Huttner WB, Schiebler W, Greengard P, De Camilli P (1983) Synapsin I (protein I), a nerve terminal-specific phosphoprotein. III. Its association with synaptic vesicles studied in a highly purified synaptic vesicle preparation. J Cell Biol 96:1374-1388.

Ikeda K, Onaka T, Yamakado M, Nakai J, Ishikawa TO, Taketo MM, Kawakami K (2003) Degeneration of the amygdala/piriform cortex and enhanced fear/anxiety behaviors in sodium pump $\alpha 2$ subunit (Atpla2)deficient mice. J Neurosci 23:4667-4676.

Kanerva L, Hervonen A, Tissari AH (1978) Ultrastructure of synaptosomes from fetal rat brain. Acta Physiol Scand 102:50-63.

Kanner BI (2006) Structure and function of sodium-coupled GABA and glutamate transporters. J Membr Biol 213:89-100.

Kawakami K, Ikeda K (2006) Modulation of neural activities by $\mathrm{Na}$, K-ATPase alpha 2 subunit through functional coupling with transporters. Cell Mol Biol (Noisy-le-Grand) 52:92-96.

Koch HP, Kavanaugh MP, Esslinger CS, Zerangue N, Humphrey JM, Amara SG, Chamberlin AR, Bridges RJ (1999) Differentiation of substrate and nonsubstrate inhibitors of the high-affinity, sodium-dependent glutamate transporters. Mol Pharmacol 56:1095-1104.

Koch HP, Brown RL, Larsson HP (2007) The glutamate-activated anion conductance in excitatory amino acid transporters is gated independently by the individual subunits. J Neurosci 27:2943-2947.

Koeberle PD, Bähr M (2008) The upregulation of GLAST-1 is an indirect antiapoptotic mechanism of GDNF and neurturin in the adult CNS. Cell Death Differ 15:471-483.

Larre I, Ponce A, Fiorentino R, Shoshani L, Contreras RG, Cereijido M (2006) Contacts and cooperation between cells depend on the hormone ouabain. Proc Natl Acad Sci U S A 103:10911-10916.

Li S, Stys PK (2001) $\mathrm{Na}(+)-\mathrm{K}(+)$-ATPase inhibition and depolarization induce glutamate release via reverse $\mathrm{Na}(+)$-dependent transport in spinal cord white matter. Neuroscience 107:675-683.

Liang M, Tian J, Liu L, Pierre S, Liu J, Shapiro J, Xie ZJ (2007) Identification of a pool of non-pumping Na/K-ATPase. J Biol Chem 282:10585-10593.

Mikoshiba K (2007) IP3 receptor/ $\mathrm{Ca}^{2+}$ channel: from discovery to new signaling concepts. J Neurochem 102:1426-1446.

Morth JP, Pedersen BP, Toustrup-Jensen MS, Sørensen TL, Petersen J, Andersen JP, Vilsen B, Nissen P (2007) Crystal structure of the sodiumpotassium pump. Nature 450:1043-1049.

Moseley AE, Williams MT, Schaefer TL, Bohanan CS, Neumann JC, Behbehani MM, Vorhees CV, Lingrel JB (2007) Deficiency in Na,K-ATPase $\alpha$ isoform genes alters spatial learning, motor activity, and anxiety in mice. J Neurosci 27:616-626.

Nakamura Y, Iga K, Shibata T, Shudo M, Kataoka K (1993) Glial plasmalemmal vesicles: a subcellular fraction from rat hippocampal homogenate distinct from synaptosomes. Glia 9:48-56.

Pawson T (2004) Specificity in signal transduction: from phosphotyrosineSH2 domain interactions to complex cellular systems. Cell 116:191-203.

Peacey E, Miller CC, Dunlop J, Rattray M (2009) The four major N- and C-terminal splice variants of the excitatory amino acid transporter GLT-1 form cell surface homomeric and heteromeric assemblies. Mol Pharmacol 75:1062-1073.

Peng L, Martin-Vasallo P, Sweadner KJ (1997) Isoforms of Na,K-ATPase $\alpha$ and $\beta$ subunits in the rat cerebellum and in granule cell cultures. J Neurosci 17:3488-3502.

Pierre SV, Sottejeau Y, Gourbeau JM, Sánchez G, Shidyak A, Blanco G (2008) Isoform specificity of Na-K-ATPase-mediated ouabain signaling. Am J Physiol Renal Physiol 294:F859-F866.

Reye P, Sullivan R, Scott H, Pow DV (2002) Distribution of two splice variants of the glutamate transporter GLT-1 in rat brain and pituitary. Glia $38: 246-255$.

Robinson MB, Dowd LA (1997) Heterogeneity and functional properties of subtypes of sodium-dependent glutamate transporters in the mammalian central nervous system. Adv Pharmacol 37:69-115. 
Ronaldson PT, Bendayan M, Gingras D, Piquette-Miller M, Bendayan R (2004) Cellular localization and functional expression of P-glycoprotein in rat astrocyte cultures. J Neurochem 89:788-800.

Schoner W, Scheiner-Bobis G (2007) Endogenous and exogenous cardiac glycosides and their mechanisms of action. Am J Cardiovasc Drugs 7:173-189.

Shigeri Y, Seal RP, Shimamoto K (2004) Molecular pharmacology of glutamate transporters, EAATs and VGLUTs. Brain Res Brain Res Rev 45:250-265.

Shull GE, Greeb J, Lingrel JB (1986) Molecular cloning of three distinct forms of the $\mathrm{Na}+, \mathrm{K}+$-ATPase alpha-subunit from rat brain. Biochemistry 25:8125-8132.

Susarla BT, Robinson MB (2008) Internalization and degradation of the glutamate transporter GLT-1 in response to phorbol ester. Neurochem Int 52:709-722.

Susarla BT, Seal RP, Zelenaia O, Watson DJ, Wolfe JH, Amara SG, Robinson MB (2004) Differential regulation of GLAST immunoreactivity and activity by protein kinase C: evidence for modification of amino and carboxyl termini. J Neurochem 91:1151-1163.

Sweadner KJ, Donnet C (2001) Structural similarities of Na,K-ATPase and SERCA, the $\mathrm{Ca}(2+)$-ATPase of the sarcoplasmic reticulum. Biochem J 356:685-704

Takayasu Y, Iino M, Kakegawa W, Maeno H, Watase K, Wada K, Yanagihara D, Miyazaki T, Komine O, Watanabe M, Tanaka K, Ozawa S (2005) Differential roles of glial and neuronal glutamate transporters in Purkinje cell synapses. J Neurosci 25:8788-8793.

Tian J, Cai T, Yuan Z, Wang H, Liu L, Haas M, Maksimova E, Huang XY, Xie ZJ (2006) Binding of Src to $\mathrm{Na}^{+} / \mathrm{K}^{+}$-ATPase forms a functional signaling complex. Mol Biol Cell 17:317-326.
Tzingounis AV, Wadiche JI (2007) Glutamate transporters: confining runaway excitation by shaping synaptic transmission. Nat Rev Neurosci 8:935-947.

Vagin O, Tokhtaeva E, Sachs G (2006) The role of the betal subunit of the $\mathrm{Na}, \mathrm{K}-\mathrm{ATPase}$ and its glycosylation in cell-cell adhesion. J Biol Chem 281:39573-39587.

Veldhuis WB, van der Stelt M, Delmas F, Gillet B, Veldink GA, Vliegenthart JF, Nicolay K, Bär PR (2003) In vivo excitotoxicity induced by ouabain, a Na ${ }^{+} / \mathrm{K}^{+}$-ATPase inhibitor. J Cereb Blood Flow Metab 23:62-74.

Williams SM, Sullivan RK, Scott HL, Finkelstein DI, Colditz PB, Lingwood BE, Dodd PR, Pow DV (2005) Glial glutamate transporter expression patterns in brains from multiple mammalian species. Glia 49:520-541.

Xie Z (2003) Molecular mechanisms of $\mathrm{Na} / \mathrm{K}-\mathrm{ATPase}-$ mediated signal transduction. Ann N Y Acad Sci 986:497-503.

Yernool D, Boudker O, Jin Y, Gouaux E (2004) Structure of a glutamate transporter homologue from Pyrococcus horikoshii. Nature 431:811-818.

Yingst DR, Yang SY, Schiebinger R (1998) Purification of active $\mathrm{Na}^{+}-\mathrm{K}^{+}$ ATPase using a new ouabain-affinity column. Am J Physiol 275:C1167-C1177.

Zelenaia O, Schlag BD, Gochenauer GE, Ganel R, Song W, Beesley JS, Grinspan JB, Rothstein JD, Robinson MB (2000) Epidermal growth factor receptor agonists increase expression of glutamate transporter GLT-1 in astrocytes through pathways dependent on phosphatidylinositol 3-kinase and transcription factor NF-kappaB. Mol Pharmacol 57:667-678.

Zhang D, Hou Q, Wang M, Lin A, Jarzylo L, Navis A, Raissi A, Liu F, Man HY (2009) Na,K-ATPase activity regulates AMPA receptor turnover through proteasome-mediated proteolysis. J Neurosci 29:4498-4511. 